Revista de la red interuniversitaria de estudios sobre las literaturas rioplatenses contemporáneas en Francia

16 | 2017

Esnobismos

\title{
Victoria Ocampo : una esnob para el desierto argentino
}

\section{Victoria Liendo}

\section{OpenEdition}

\section{Journals}

Electronic version

URL: http://journals.openedition.org/lirico/3761

DOI: $10.4000 /$ lirico.3761

ISSN: 2262-8339

\section{Publisher}

Réseau interuniversitaire d'étude des littératures contemporaines du Río de la Plata

\section{Electronic reference}

Victoria Liendo, «Victoria Ocampo : una esnob para el desierto argentino », Cuadernos LIRICO [En línea], 16 | 2017, Puesto en línea el 07 octubre 2017, consultado el 19 abril 2019. URL : http:// journals.openedition.org/lirico/3761 ; DOI : 10.4000/lirico.3761

This text was automatically generated on 19 April 2019

\section{(c) (†) $\odot$}

Cuadernos LIRICO está distribuido bajo una Licencia Creative Commons Atribución-NoComercialSinDerivar 4.0 Internacional. 


\title{
Victoria Ocampo : una esnob para el desierto argentino
}

\author{
Victoria Liendo
}

Il est impossible de comprendre et de punir à la

fois.

PAUL VALÉRY, Rhumbs, 1926.

1 Se cumplen noventa años desde la primera vez que se calificó a Victoria Ocampo de esnob en la prensa argentina. La siguieron muchas más. Casi un siglo de unir indiscutiblemente ese nombre a ese mote: desde 1927 hasta hoy, aquel joven adjetivo, quizá el más escurridizo y sin dudas el más cambiante de la lengua, cae sobre su figura con la naturalidad de una fruta que cae del árbol. Pero esta asociación -esta caída-, cuya insistencia a través de los años denota una terquedad digna de la mismísima Victoria, no es natural sino opaca, y no por eso menos eficaz. El fenómeno es curioso sólo cuando se lo observa de cerca ; de lejos, nadie cuestionaría una afirmación que, si bien no sería fácil argumentar de manera objetiva sin tropezar con los más estrechos clichés de la historia cultural argentina (como es, por ejemplo, la palabra "extranjerizante"), tampoco deja de parecernos una operación segura y espontánea. A fin de cuentas, cómo y cuándo o en qué forma y sentido fue Ocampo esnob, poco importa; que lo fue, parece irrefutable. Sin embargo, la constancia de esta certeza encierra su paradoja : ¿cómo es posible que una noción tan inestable como es la de "esnob" -que sólo puede definirse a través de una posición y un contexto siempre variables- adquiera una estabilidad categórica en la figura de Ocampo?

2 No puede decirse que, durante el medio siglo que duró su trayectoria (de 1920 a 1978), la Argentina no haya atravesado profundos períodos de transformación. Cambian los gobiernos. Cambian las épocas y con ellas cambian la sociedad, la cultura, la lengua. Cambia asimismo el lugar que la directora de SUR va a ir ocupando en el campo cultural argentino y, sin embargo, que sea a los treinta años, cuando está empezando su carrera, a los cincuenta, cuando alcanza una centralidad contundente, o a los setenta, en pleno ocaso, la fustigación anti-esnob permanece intacta. Quizá no sea vano agregar que esta constante no solamente atraviesa diferentes períodos históricos, sino que tampoco 
distingue entre izquierdas y derechas : ya en los años 20, académicos conservadores que escribían en La Nación coincidían excepcionalmente con jóvenes socialistas que publicaban la revista Claridad en tildarla de esnob ${ }^{1}$. Algo parecido pasaría más tarde con SUR. Al evocar los años de la guerra civil española, Ocampo recuerda : "Sur tenía fama de comunistoide entre los conservadores (la oligarquía) y de fascista entre las izquierdas". Lo mismo rememora José Bianco, secretario de redacción de la revista durante veintitrés años (de 1938 a 1961) :

En aquella época [1937], para los reaccionarios, Sur era una revista de izquierda ; para los izquierdistas, una revista de derecha. Es inevitable. No se puede ser independiente sin caer en el desfavor de lo que Sartre llamaba "los bien pensantes de derecha e izquierda. ${ }^{3}$

"No podemos (aunque los comunistas y los nacionalistas lo anhelen) think her away", escribe Borges en 1962. La frase de Sartre, Bianco la toma de un texto de homenaje que el filósofo francés escribe para André Gide, que ha muerto5. La cita original dice : "il a su réaliser contre lui l'union des bien-pensants de la droite et la gauche"6. El esnobismo entendido como una frivolidad o una pose incapaz de asumir un compromiso- fue quizá, en el caso de Ocampo, el que hizo posible la improbable unión entre dos ideologías enfrentadas. El no pertenecer enteramente a ninguna facción hizo que fuera más fácil, tal vez, adjudicarle el esnobismo como único partido, convirtiéndola a ojos de muchos en una mujer sin rumbo, un poco corrompida, seguramente, por su borrosidad frente a categorías políticas bien definidas. En palabras de Enrique Anderson Imbert :

Fascistas y comunistas, patrioteros y católicos, hispanófilos y telúricos, profesores anti-vitales y energúmenos anti-racionales, señoritos satisfechos y resentidos hombres-masa, agarrados como están a sus respectivas facciones, al ver que Victoria se desvía de todas ellas se quedan sin saber quién es. La creen una descarriada. ${ }^{7}$

4 Treinta años después de su fundación, el ataque de Contorno contra SUR, si bien apunta a discutir cuestiones más serias que el axiomático esnobismo de su fundadora, no puede sino recurrir a ese golpe fácil para asegurarse el tiro de gracia. El artículo que Adelaida Gigli publica en 1954 es un excelente ejemplo, sobre todo por el simpático detalle de que, en algunos pasajes, al juzgar frívolos los Testimonios de Ocampo (que ha leído), la intelectual comprometida deja entornada, sin darse cuenta, la puerta de su propio esnobismo: cuando el lector -la misma Gigli- espera que Victoria le revele "eso" "de [Paul] Valéry, de Emily [Brontë]" (mezcla de secreto y "no sé qué" que define como "el encanto, la difícil circulación"), la directora de SUR lo -la- defrauda precisando en cambio "la nota deliciéuse [sic] de un té" de los ochenta años indignada frente al reportaje que publica la revista Atlántida, de tiraje masivo, describiéndola como una perfecta esnob que dice "flowers" en lugar de "flores" y "friends" en lugar de "amigos", que es "coqueta", usa perfume Miss Dior y boquilla, tiene muebles ingleses del siglo XVIII, vajilla de Sèvres, banquitos de gamuza comprados en Hermès y toma el té a las cinco de la tarde en punto9. "¡Ave María purísima!", se estremece Victoria al leerlo; por supuesto, lo que desde una mirada popular podía leerse como el retrato de una esnob, a sus ojos no podía ser sino "una profanadora cursilería"

5 Victoria Ocampo esnob, sí, ¿pero por qué ? ¿Porque le gustaba contar cómo un re bemol de Debussy la hacía entrar en éxtasis o porque no se cansó de repetir, una vez que lo descubrió, que tenía una antepasada guarani ${ }^{11}$ (el buscado detalle chic de las más ilustres genealogías patricias) ? ¿Porque entremechaba en sus textos palabras extranjeras y hacía declaraciones públicas del estilo "me molesta pensar en francés" 12 o porque publicaba a 
Saint-John Perse y a T. S. Eliot? ¿Por sus crónicas, quizá, en las que supo anudar, con un estilo "entre nos" propio de su clase, literatura y mundanidad $?$ ¿O acaso porque su gusto moderno fue indiferente a las provocaciones de la vanguardia, y así como ignoró a un escritor como Gombrowicz, sin credenciales parisinas, tampoco se dejó seducir por la música de Schönberg ni le prestó la menor atención a la Escuela de Viena ${ }^{13}$ ? Se puede seguir esta lista por varias páginas, pensar incluso en reproches nuevos, nunca oídos, preguntarnos por qué escribió sobre su romance con Drieu la Rochelle pero nunca contó nada de las noches que pasó con Mallea. Ni siquiera mencionó las iniciales de Vicente Almandos Almonacid, aquel piloto argentino que le robó un beso en un taxi después de haberla llevado a dar vueltas en avión ${ }^{14}$. ¿Significa que prefirió ser conocida por sus amantes europeos? ¿O que eligió borrar de los argentinos a todos menos a Julián Martínez, un hombre de su misma clase que nada tenía que ver con el mundo de las letras y fue, a pesar del escándalo, su única relación duradera? Lo cierto es que Victoria Ocampo no rechazó todas las creencias de su clase y tuvo, además, esporádicos y triviales gestos esnobs (en el artículo que le dedicó al tema confiesa algún que otro rapto controlado ${ }^{15}$ ). Pero lo que cultivó con devoción y rigor ascético fue el esnobismo de la modernidad, un esnobismo generacional, de contornos claros y específicos, cuyas particularidades se han ido perdiendo en la proyección colectiva, indiferenciada y longeva que eclipsa su figura. Contra el epíteto monótono y obstinado que le tocó en suerte, comienza el trabajo de despejar, clasificar y poner orden.

\section{Ese oscuro objeto del esnobismo}

El esnobismo, como tantos "ismos" que involucran pasiones y prejuicios, no se puede explicar en pocas palabras sino a través de innumerables ejemplos, y si se resiste a una definición estable es porque es subsidiario de un marco relacional específico que exprese cada vez su matiz particular -y diríase incluso puntual (yendo más lejos, algo similar sucede con el peronismo). Corrado Fatta lo presenta como un delito del que no se sabe absolutamente nada, y si, para el autor italiano, las más sonsas boutades pasan fácilmente por definiciones es porque es un tema que parece más dispuesto a "émouvoir le sentiment qu'à stimuler la réflexion" ${ }^{16}$. En este sentido, es quizá más productivo pensar en una historia del esnobismo que en un denominador común de todos los esnobismos, teniendo en cuenta que es un fenómeno que evoluciona al ritmo de la sociedad en la cual se manifiesta. De esta premisa parte Frédéric Rouvillois al encarar el estudio de su historia : "le snobisme n'existe que par les snobs" ${ }^{17}$, declara, y los esnobs son tan distintos unos de otros como varía aquello con lo que sueñan -y es que, para este autor, el esnobismo es ante todo una fantasía, "un rêve d'une grandeur souvent illusoire ou imaginaire"18. En 1896, en cambio, Pierre Veber, novelista francés, proponía pensarlo como un estado de ánimo ("un état d'âme" ${ }^{19}$ ) y es que, en efecto, mucho más que un sueño y que un atributo, como se lo suele entender, el esnobismo es una actitud -un modo de conducirse que suele ser circunstancial, caprichoso e irracional, pero también, aunque más raramente, puede estructurar una ética, ser aplicado y coherente. Si resulta arduo definir esta actitud en una sola frase es porque, más antigua incluso que el nombre que Thackeray le dio en 1846 en la revista londinense The Punch, desde entonces y hasta ahora ha sabido declinar su significado -su referente- de las más diversas y variadas maneras sin nunca abandonar aquel primer y único significante inglés : "snob". Esto no impidió, hay que agregar, que nuevas palabras se crearan en otras partes del mundo para nombrar las versiones locales 
del fenómeno, personajes que, como la mujer que sueña el poema de Verlaine, "ne sont, chaque fois, ni tout à fait les mêmes ni tout à fait des autres": cajetillas, rastacueros, cursis, huachafos o siúticos, todos son avatares latinoamericanos del primer esnob ${ }^{20}$. High-brows y dandis, en cambio, parecen haber surgido en Inglaterra como alter egos preocupados por diferenciar un tipo de esnobismo de otro (el primero intelectual, el segundo de la moda).

7 Pero si olvidáramos las particularidades distintivas de uno y otro y ensayáramos una definición de base, podríamos empezar con Virginia Woolf, para quien la esencia de este fenómeno reside en la voluntad de querer impresionar a los demás, y agregarle el detalle crucial que señala Joseph Epstein, el de buscar obtener a cambio algún tipo de crédito simbólico : "anyone who thinks himself superior in a way that demands recognition" 21 . Si bien el esnob parece tener los ojos fijos y embelesados en su fantasma, al que nunca deja de mirar es al que tiene en frente, al que quiere impresionar, al que necesita para poder sentirse superior. Nótese incluso que el inferior, contra el cual se demarca el esnob, es muchas veces el mismo al que después este último va a exigirle reconocimiento : es el caso de Odette Swann, que, cuando consigue entrar en el beau monde, se preocupa por invitar a una de sus viejas amiga del demi-monde, la única capaz de atestiguar su ascensión social. La actitud de ostentar una superioridad (se posea o no se posea tal pertenencia) implica necesariamente un desprecio hacia abajo. En este sentido va la definición de Rouvillois :

Le snobisme n'est pas simplement l'attitude qui consiste à vouloir ressembler, par son nom ou son appartenance, ses goûts, ses opinions o ses comportements, aux membres d'un groupe que l'on juge supérieur. C'est aussi, subsidiairement, le fait de se permettre de mépriser tous ceux qui n'appartiennent pas au clan, et que l'on peut donc considérer comme des gens communs, des arriérés, des inférieurs ${ }^{22}$.

Dicho de otro modo, esnob es quien logra hacer de dos carencias una posesión : busca parecerse al superior que admira (carece de esa identidad, aunque la tenga, desde el momento mismo en que la ostenta) y busca impresionar al inferior, que muchas veces no es sino su par, o sea él mismo (y es que en el desprecio del esnob por el vulgar se esconde muchas veces un desprecio de $s^{23}{ }^{23}$. De la primera carencia se desprende la pose, la impostura y la pretensión, de la segunda la altivez, y de ambas la vanidad. El esnob no tiene más que una admiración y un desprecio, pero con ambos diseña una identidad. Ahora bien, esta identidad pretendidamente estable se construye a través de objetos inestables, y más aún, de un marco siempre cambiante que permite el despliegue de múltiples esquemas, incluso en una misma interacción social. En este sentido, Goldgel habla, por un lado, del "carácter posicional" del fenómeno ("su significado varía de acuerdo a las series de relaciones sociales a través de los cuales se articula" ${ }^{24}$ ) y, por otro, de su naturaleza relacional ("la identidad del esnob es siempre relacional : sólo se puede ser esnob a través de la mirada de los otros -y por lo tanto de acuerdo con las jerarquías sociales en uso, en sí mismas construidas sobre la base de antagonismos" ${ }^{25}$ ). El mismo objeto, dependiendo desde dónde se lo mire, puede ser interpretado como un emblema de distinción o denotar una marca de inferioridad. Goldgel toma el ejemplo del rastacuero, visto por sus compatriotas como un exitoso esnob cosmopolita y por los europeos como un vulgar nuevo rico latinoamericano. Corrado Fatta, por su parte, analiza la relatividad del objeto esnob en lo que concierne al valor de la elegancia, que nunca es igual en capital que en provincia (tampoco en ciudades termales que en ciudades balnearias) : lo que para Madame Swann es elegante, explica, no lo será necesariamente para la duquesa de 
Guermantes ; ahora bien, todo que la segunda crea elegante, lo será sin excepción para la primera $^{26}$. Siempre es una cuestión de jerarquía y grados.

Tomado como objeto de estudio, el esnobismo permite los más variados recortes. Se puede rastrear su historia, como hizo Frédéric Rouvillios ${ }^{27}$, hacer un ingenioso catálogo de casos, al estilo de Arthur Koesler en "An essay on snobbery", o pensar en un diccionario, como se le ocurrió a Philippe Jullian ${ }^{28}$. También el duque de Bedford publicó un manual prometiéndole garantías de éxito a cualquier esnob improvisado (que Ocampo lee y comenta : "el libro del duque de Bedford (por la gracia que me hizo) es de los que me gustaría traducir ; pero tal vez sea mejor tratar de dar a nuestros lectores un ensayo sobre los snobs que se ajuste a las modalidades argentinas" ${ }^{29}$ ). Corrado Fatta ${ }^{30}$ propone pensarlo como un capítulo de antropología (que le dedica a Giuseppe Tomasi di Lampedusa y encabeza con un epígrafe de Nietzsche). Se puede también intentar una definición a partir de la filosofía de la moral, interrogando su sistema de creencias, como hace Emryes Westacott en The virtues of our vices, o aplicarlo a un campo, a una disciplina y a un contexto determinados -es el caso de Carassus ${ }^{31}$, que lo estudia en la literatura francesa de la últimas décadas del siglo XIX y las primeras del XX, o el de Sean Latham ${ }^{32}$, que se preocupa por investigar qué funciones cumple en la novela moderna inglesa. Cerca de esta línea, en su artículo "Entre dandis y rastacueros. Aproximaciones al esnobismo del siglo XIX latinoamericano", Víctor Goldgel lo estudia desde una perspectiva periférica, haciendo foco en los problemas de la importación cultural en América Latina. Existen también trabajos que se ocupan de dejar el testimonio de un esnobismo de época, es decir, los que reconstruyen un momento específico de la historia cultural a través de esta noción: así lo hace con maestría Elena Croce en su breve libro Lo snobismo liberale, desentrañando el caso de Italia, o Joseph Epstein ${ }^{33}$ con su célebre versión americana. No hace otra cosa Jacques Boulenger en Monsieur ou le Professeur de snobisme, donde reporta los prejuicios demodés de sir Richard Hawcett, asiduo personaje de un conocido bar parisino de la primera década del siglo XX, que en 1921 "ganan un cierto color histórico y un aspecto 'd'avant-guerre' capaz de atraer a los curiosos"34 (su hermano Marcel ${ }^{35}$, por otra parte, escribe un Éloge du snobisme un lustro después; nótese que ya en 1907, Jacques había publicado Sous Louis-Philippe : Les Dandys con prefacio de Marcel $^{36}$ ). La reivindicación del esnobismo desde el elogio deriva muchas veces en narraciones rancias de espíritu reaccionario, como es el caso de Jacques de Ricaumont ${ }^{37}$, que se sirve de este enfoque para transformar su experiencia biográfica en una apología de clase. En otra línea, el famoso ensayo de Virginia Woolf, "Am I snob?", donde discurre sobre su esnobismo social, o incluso "Middlebrow", donde se indigna frente al esnobismo intelectual, guardan en sus páginas el pulso del debate cultural de su tiempo -lo mismo sucede con "Hunting the high-brow", de su marido Leonard Woolf, o con "Foreheads Villainous Low" y "Selected Snobberies" de Aldous Huxley, amigo que la pareja inglesa compartía con Victoria Ocampo. Bien enmarcados en una época pero ya rozando la autoficción, libros como Monsieur Croche antidilettante de Claude Debussy tratan la cuestión desde una óptica cómica (y no por eso menos pedagógica) que combina ironía, vituperio y gracia.

El esnobismo es un tema que nunca ha pasado de moda, probablemente por su irremediable vigencia en la vida cotidiana. No hay valores -sean políticos, sociales, religiosos o culturales- que puedan dejar a una persona exenta de tener, en un momento u otro, un rapto esnob. "All men are snobbish about something"38 dice el famoso íncipit de Aldous Huxley ("One is almost tempted to add: there is nothing about which man cannot feel snnobish", es la segunda frase ${ }^{39}$ ). Raphaël Enthoven proponía directamente 
cambiar la pregunta “¿soy esnob ?" por “¿cuándo es que soy esnob ?" entrevista que publicó con Adèle Van Reeth, después de dedicarle al tema cuatro emisiones de radio en France Culture, que el esnobismo es una "una debilidad, una pasión triste, una esclavitud" ${ }^{41}$. Pero dice también : "Toute maladie comporte ses avantages" Gombrowicz no lo entendía de otro modo. Sabía que, por mucho que los valores democráticos se proclamaran vencedores, la aristocracia era un tigre contra el cual había necesariamente que defenderse (" $\mathrm{i} C u a n d o$ tienes que defenderte de algo, es evidente que ese algo existe! Las cosas no siempre van tan bien como quisiera la bonachería democrática"43) ; lo mismo apunta Arthur Koestler en su ensayo sobre el esnobismo :

But the archetypal roots of the older values, and their symbols of noble kings and fair princesses, robber barons and chivalrous knights, have survived and constantly interfere with our liberal and democratic outlook. Pomp and circumstance, rank and consequence, title and lineage, have remained with us as a kind of psychological black-market currency under the social counter. ${ }^{44}$

11 Consciente de esta realidad de la psicología social, el escritor polaco había descubierto ya en los años 30, en Varsovia, el arma secreta que se escondía en el esnobismo : igualar a todos en la estupidez. Por eso, y porque su gusto por el duelo y la contradicción era enérgico, se sienta en la mesa de los jóvenes poetas marxistas de vanguardia del café Ziemianska y empieza a sembrar discretamente pequeños gestos esnobs en la conversación : comenta "como quien no quiere la cosa" que su abuela era prima de los Borbones de España, le pasa el azúcar "cortésmente" al hijo del coronel de buena familia (y no al líder de la mesa, de clase más baja) y apoya las opiniones de Stefan, de padres terratenientes. Sus compañeros de mesa -que, aunque pertenecían a diferentes corrientes (algunos eran proletarios del social-realismo, otros vanguardistas o surrealistas), se declaraban todos libres de prejuicios ("¡los estúpidos esnobismos del ocaso de la burguesía!", los escucha decir Gombrowicz cuando llega)- protestan o bostezan frente a las boutades del joven iconoclasta. Pero no tardan mucho en ir cayendo uno por uno, disimuladamente, al fondo de su propio esnobismo -y ya uno comenta que su abuelo tiene una villa en Konstancin (una suerte de San Isidro polaco), otro que su abuela era "de campo" y un tercero, "como jugando", se pone a dibujar su escudo de armas en una servilleta de papel. “¿Qué está haciendo? ¿qué sabotaje es este? -lo increpa alarmado al final Broniewski, reconocido poeta de izquierda- $¡$ Usted ha logrado contagiar de heráldica hasta a los comunistas !"45 $\mathrm{Ni}$ el mismo Gombrowicz puede resistirse a esta manía que padece y propaga, y si, ya en Buenos Aires, huye asfixiado de una reunión social en casa de una familia de la oligarquía argentina, su primer reflejo es entrar en su café "de bajo monto" y decirle a sus conocidos que juegan a los dados y toman vino Toro : "Vengo de..." ${ }^{46}$.

En el caso de Gombrowicz, se trata de un esnobismo social que en una Polonia sármata y decadente no podía sino florecer con esplendor. Hay otros: mundano, intelectual, cosmopolita, nacionalista, de la vanguardia, de la academia, de la moda, de la religión, de la música, del deporte, del cine y tantos más. Estos, a diferencia del primero, se caracterizan por adorar un objeto volátil y siempre proteico. "Le snobisme, en changeant d'objet, ne change pas d'accent ni de nature" ${ }^{47}$, dice Rouvillois citando a Proust. Por supuesto, distintos esnobismos pueden ser combinables, y del fantasma de "la clase alta" se puede pasar al del arte o al de la moda, y así indefinidamente. Cada esnob construye su propio esnobismo con el fin de distinguirse $-y$ muchas veces lo logra. Ese es el gran descubrimiento de Thackeray -descubrimiento que lo sume en una terrible angustia, dice Sean Latham: su legendario Mr. Snob, que había sido creado para ridiculizar las 
pretensiones sociales de la clase media y elevar asimismo a la nobleza inglesa, llega a seducir a tal punto a su audiencia (y a su autor) que termina convirtiéndose en una figura poderosa, "a witty paragon of superior taste, well aware of cultural capital's profitability" ${ }^{48}$. El sistema de prestigio social se devela a través suyo como una red sin más fundamento que la moda. Es útil recordar, en este sentido, las dos categorías que distingue Víctor Goldgel : el que se sale con la suya y el que no, es decir, el esnob impugnado (el cursi, el ridículo) y el esnob victorioso (el dandi, el chic). En Victoria Ocampo, nótese, ambos tipos convergen y si en un principio se la ve como una esnob empoderada (como sucede en la parodia que le dedica Marcos Victoria en $1934^{49}$ ), a medida que avanzan los años se va transformando en una esnob grotesca (los citados artículos de Gigli y de Atlántida sirven de ejemplo). Ahora bien, además de todos estos recortes y perspectivas a partir de las cuales es posible acercarse al oscuro objeto del esnobismo, existe una división fundamental para estudiar el caso de Victoria Ocampo: la que separa el esnobismo que ella asumió y encarnó del que sus contemporáneos proyectaron en su persona y los que vinieron después siguieron recalcando sobre su figura.

\section{Mujer, rica, diletante y cosmopolita}

13 A los ochenta años, Ocampo reconoce lo que ya sabía a los treinta : "No les guardo rencor a los que me han atacado. Mi puesto se prestaba al jeu de massacre" $"$. Podemos imaginar por qué : los cuatro puntos cardinales más visibles de su figura (mujer, rica, diletante y cosmopolita) dibujan "la cruz de SUR", suerte de constelación y viacrucis que puede guiarnos en la comprensión de la masacre.

Empecemos por calibrar la gran visibilidad pública que tenía esta mujer en Buenos Aires incluso antes de 1927, cuando arranca su activismo musical alrededor de la APO (Asociación del Profesorado Orquestal). En su juventud, Ocampo era lo que hoy podríamos llamar una elegante it-girl. En 1923 sale en Plus Ultra, el suplemento cool de Caras y Caretas, un retrato de ella que hace Anselmo Miguel Nieto ${ }^{51}$ (tres años antes publica "Babel", su primer artículo en La Nación). En 1922, aparecen las primeras fotos de Victoria manejando. Ya desde antes asistía a conferencias como una auténtica bas bleu porteña ; así lo conoce a Ortega y Gasset en 1916. En 1929, al comienzo del gran viaje que organiza el lanzamiento de la futura SUR, aparece fotografiada por Van Riel en revistas mundanas del “'Tout Sud-Amérique' de Paris" [sic] : enmarcan su retrato dos paratextos; un título, "Elegancias argentinas", y un copete : "La Sra. Victoria Ocampo, una de las más elegantes figuras mundanas de Buenos Aires y una de las más prestigiadas escritoras argentinas quien acaba de publicar un libro en francés sobre las mujeres de Dante" ${ }^{52}$-los recuerdos que de ella registra Carlos Morla Lynch en Madrid de 1931 también acentúan este perfil "de alta intelectualidad"53.

15 Con los años y la labor de una empresa demasiado exitosa para sus expectativas, aquella primera y fresca notoriedad se solemniza y no tarda mucho en convertirla en un personaje importante de la cultura. "Durante mucho tiempo la conocí sin conocerla" ${ }^{4}$, dice José Bianco en el homenaje que le dedica dos años después de su muerte ; como él, o Sebreli ${ }^{55}$, muchos son los que la ven por primera vez dando una conferencia. Incluso personas que la conocían bien, como Eduardo Mallea, podían sentir esa sensación de "conocerla sin conocerla" :

Más de una vez la vi, como si no la hubiera conocido nunca, destacada en toda su

figura, imagen independiente que se movía como el ser extraño que a nuestros ojos 
actuara proyectando a lo lejos sin que supiera que lo estamos mirando, ella iluminada y nosotros a oscuras. ${ }^{56}$

Basta leer el texto de Bianco para darse una idea de lo que producía Victoria en persona, en vivo y en directo : una capacidad de persuasión que no necesitaba de palabras y que Bianco localiza en "su innata aristocracia", en su "porte", en su "presencia" (todo esto en una mujer que era, además, muy alta, "a very tall, extremely beautiful woman, she looks like an Amazon" ${ }^{57}$, escribió sobre ella Waldo Frank ; "el mejor elogio que recibí en mi vida y que recuerdo con más alegría -dirá Ocampo en 1968- ocurrió a los 20 años. Iba caminando por la calle Florida y un grupo de hombres parados en una esquina me gritaron 'Adiós, Botafogo'. Como usted recordará, era el nombre de un famoso caballo de carrera. Era, sin dudas, un gran cumplido"58); dice Bianco acto seguido: "no necesitaba hablar para traslucir inteligencia" ${ }^{59}$ (Morla Lynch también alude a su "innata inteligencia" y a un cierto "hermetismo de esfinge" que no logra "penetrar" ${ }^{60}$ ).

Si bien el secretario de redacción de SUR sabe reconocer los defectos de su jefa (y parece conocerlos bien), su relato está indudablemente marcado por el afecto y por una admiración cuyas dimensiones parece terminar de comprender a medida que escribe la frase final: "Quizá Victoria no fuera un genio; sin embargo, qué duda cabe, para los hombres de letras argentinos era el genio tutelar de este país" ${ }^{61}$. Y no sólo para "los hombres de letras argentinos", también para las mujeres de a pie. Dos frases que comentan Borges y Bioy sobre la manera de hablar de las porteñas son : "En Buenos Aires las mujeres se habían puesto a escribir. Una señora le dijo a Borges: 'Antes de Victoria, esto no se usaba"” ${ }^{62} \mathrm{o}$ "Dice [Borges] que una frase nunca oída es : ‘ ¿Victoria Ocampo ? No la ubico"'63. Si uno lee Gombrowicz, por dar un ejemplo alejado de su círculo de sociabilidad, se da cuenta de que -si bien esta comparación vale única y estrictamente en términos de establishment institucional- lo que Lugones significaba para los martinfierristas, ella lo fue después para los ferdydurkistas ; no por nada Witold grita la frase “¡Maten a Borges!" desde la cubierta del barco que lo llevará de vuelta a Europa, pero en su panfleto vanguardista "Aurora" deja por escrito la sentencia " $i$ Muerte a Victoria Ocampo !" ${ }^{64}$. Sebreli, otro excluido ${ }^{65}$, se arrepiente, ya viejo, de no haber sido más lúcido respecto de Ocampo, de haberse peleado con ella ("malgasté esa oportunidad con V. O. en discusiones inútiles, diálogo de sordos") cuando más valía la pena frecuentarla : "comenzaba a convertirse a mediados del siglo XX, cuando yo la conocí, en un arquetipo histórico, único e irrepetible, una figura legendaria" ${ }^{66}$. Como muchos otros escritores de su generación -"jóvenes a mitad de siglo" y "enrolados en la literatura entonces llamada comprometida, obsesionados por la angustia existencial" ${ }^{\prime 6}$-, en esos años en que era fácil encontrarla a Victoria caminando por la calle Viamonte, donde estaba SUR y la librería francesa Galatea, todavía no habían leído a Proust ; sus fascinaciones pasaban por Sartre y figuras femeninas del estilo de Simone de Beauvoir. Sólo después de leer La Recherche se dieron cuenta de que habían tenido delante de sus ojos a una versión argentina de la duquesa de Guermantes y no habían sabido ver en ella nada más que a una ordinaria oligarca (algo similar les pasó con Borges, que en los años 50 les "era ajeno" -incluso Contorno prefería atacar a Mallea, que tenía para ellos más influencia y visibilidad- hasta un día de 1955 en que corren a Galatea a comprar el último número de Les Temps Modernes y descubren, estupefactos, que la revista de su ídolo intelectual publica, traducidos al francés, varios ensayos de Otras inquisiciones $\left.{ }^{68}\right)$. Muchos habrán reconocido, aunque fuera demasiado tarde, "el lado proustiano" de Ocampo, pero Sebreli fue el único que tuvo la agudeza de confesarlo : "Victoria Ocampo era por cierto una oligarca, pero no todos los 
oligarcas fueron Victoria Ocampo"69. No todos -qué duda cabe, diría Bianco- pero no fue la única excepción.

\section{El esnobismo es un matriarcado}

18 Existieron muchas mujeres latinoamericanas que, como ella, combinaron linaje, fortuna y ambición intelectual. Verdaderas musas de los más célebres nombres del arte y la literatura, fueron también mecenas. Millonarias, financiaron todo tipo empresas de desarrollo cultural ; escribieron libros, fundaron revistas. La mexicana Antonieta Rivas Mercado fue clave en las primeras décadas del siglo XX en su país: promocionó la Orquesta Sinfónica de la Ciudad de México, la importante revista Contemporáneos (de cuyo grupo formó parte) y el Teatro Ulises. Su trayectoria evoca la de Victoria (tradujo al español, por ejemplo, a Waldo Frank y a Jules Supervielle) con la diferencia de un detalle biográfico que, en el caso de Antonieta, suele recordarse más que sus escritos: en 1931, entra a Notre-Dame de Paris con la pistola que le había robado la noche anterior a Vasconcelos ${ }^{70}$, su amante, y se pega un tiro enfrente del famoso altar. Podemos mencionar también a Laurinda Santos Lobos en Brasil, a Eugenia Huici de Errázuriz en Chile o a Susana Soca en Uruguay, editando su mítica revista La Licorne en los años 40 en París. Incluso en Argentina hubo importantes mujeres de la alta sociedad cuyos nombres han sido olvidados a pesar de haber dejado obra escrita, como París o Recuerdos dispersos. De 1887 a 1923 de Elvira Aldao de Díaz o Un cierto París, 1942-1944 de Lucrecia de Oliveira Cézar de García Arias, por mencionar dos ejemplos de distintas épocas. Más aún, hubo mujeres que no dejaron obra, pero fueron, no obstante su actual invisibilidad, las verdaderas pioneras de la modernidad en Argentina, a saber, aquellas que fundaron y promovieron la asociación "Amigos del Arte" entre 1924 y 1942: Adelia de Acevedo (su primera presidente), Elena "Bebé" Sansinena de Elizalde (su legendaria directora), Nina Elizalde Barlett, Antonieta Silveyra de Lenharson, Magdalena Bengolea de Sánchez Elía, las hermanas Josefina y Adela de Atucha Llavallol (que se casarían ambas con nobles europeos, la primera con un marqués francés y la segunda con un conde español), las Del Carril, Delia y Adelina (respectivas mujeres de Neruda y de Güiraldes), las de Alvear Cambaceres, Elvira y Dora, personajes celebrados en el París de los años 20 (cuyo padre era el dueño de Botafogo, el purasangre que hizo leyenda en 1917), y, por supuesto, Victoria Ocampo (una Victoria joven, antes de SUR, y una aún más joven María Rosa Oliver).

19 Como lo explica Elena Croce, la élite de los años 20 y 30 era un mundo de mujeres, y el esnobismo modernizador que impulsaron fue un verdadero matriarcado: "Questa immagine di élite era un'elaborazione eminentemente femminile" ${ }^{11}$. En Más allá del ruego: vida de Susana Soca, Juan Álvarez Márquez evoca a las "amazonas intelectuales", mujeres que creaban sus propias redes: "el París de las expatriadas, de las comunidades de mujeres americanas que buscaban allí libertades que en sus países de origen no tenían"72. Anne Ansermet, hija del compositor suizo que viaja con sus padres al Buenos Aires de los años 20 , escribe en sus memorias :

En Argentine, à part quelques exceptions, l'intérêt des 'messieurs' était accaparé par des valeurs que représentaient leurs taureaux ou des amusements frivoles, et la culture de l'esprit était le partage des femmes. ${ }^{73}$

Quiénes fueron estas mujeres, dónde quedaron sus huellas y qué rol jugaron en la trayectoria de Victoria Ocampo son tres preguntas esenciales para entender tanto el difundido juicio de "esnob" que quedó inextricablemente asociado a su figura como su 
propia relación con dicho fenómeno social en el marco de un matriarcado que dirigió la importación y el desarrollo de la modernidad cultural en Argentina.

Todas presentan biografías impresionantes, con detalles novelescos y centelleos mundanos: las de Alvear, por ejemplo, habían sabido ser jóvenes, bellas y despilfarradoras en el París de los años 20, que vivieron con vistosa intensidad (Sebreli cuenta que eran conocidas en las más lujosas boutiques parisinas "como una de las tres A -Anchorena, Álzaga y Alvear- por pertenecer a esas familias argentinas ricas y gastadoras"74). Elvira, la menor, famosa musa de Borges (la retrató en "El Zahir", en "El Aleph", en "El congreso" y le dedicó un poema que empieza con el verso "Todas las cosas tuvo y lentamente todas la abandonaron"), fue antes amiga de Léon-Paul Fargue, de [James] Joyce, de Paul Valéry. Hacia 1930 se había instalado en París, donde vivió durante siete años en un palacio con una mangosta de mascota ${ }^{75}$. Llegó a financiar Commerce, por dar un dato inesperado, y publicó en París, tres meses después de que SUR saliera en Buenos Aires, la revista Imán, impresa en alta y cara calidad con Alejo Carpentier como secretario de redacción, de la que sólo existió el primer número ${ }^{76}$. Con el tiempo, como dice el verso de Borges, fue perdiendo todo lo que tuvo. La plata, como les pasó a casi todas esas viejas familias de la oligarquía argentina, un día se acabó. Elvira quedó postrada en su casa, al sur de la ciudad, obesa y desmemoriada : su amigo escritor, que de joven se entusiasmaba haciéndole preguntas sobre los ratos pasados con Joyce en París, de viejo le fue leal y cada 31 de diciembre la visitó en su casa de la calle Independencia. Confundida, como la hija anciana del cuento "La señora mayor", Elvira tocaba una campanita de plata llamando con impaciencia a un servicio que hacía tiempo había dejado de existir. Este detalle emocionaba a Borges ${ }^{77}$. El final de Dora, la hermana mayor, es quizá más triste, ya que pierde hasta el apellido pero no la memoria : "famosa por su antigua prodigalidad y belleza, sus automóviles, su alcoba cristalina, sus amores, sus escándalos, hoy trabaja de mucama en el hospital Alvear. Por pudor se hace llamar Dora Cambaceres" ${ }^{78}$.

Las biografías de las hermanas de Atucha, si bien con finales menos desdichados, no se quedan atrás : Josefina, la mayor, aparece en las memorias de Diana Vreeland, directora de Vogue, como una de las dos mujeres mejor vestidas de la Argentina (la otra era Eva Perón, lo que no es raro si pensamos en la figura del Dr. Ignacio Pirovano, casado con Lía Elizalde de Sansinena, hija de "Bebé", que en los 30 había vivido en París, en 1932 había fundado la célebre casa de diseño y decoración Comte, en 1937 había sido el primer director del Museo Nacional de Arte Decorativo y a fin de los 40 se convirtió en el gran taste-maker de primer peronismo : cuando muere Eva, se ocupa de hacer la mise en scène de su funeral) ${ }^{79}$. Es en casa de Josefina ("Jo A." la llama Victoria en las cartas que le manda a su hermana Angélica desde París), en enero de 1930, que Ocampo conoce a Lacan, con quien saca chispas enseguida y vive al menos unos días de infatuation mental ${ }^{80}$; en febrero del mismo año, toma allí el té con el grupo de Documents, la revista que rompía con el surrealismo y dirigía entonces Georges Bataille ${ }^{81}$. Pero sobre la que vale la pena detenerse brevemente es en "Tota”, como le decían a Adela, la menor de las Atucha.

Adela "Tota" de Atucha, Condesa de Cuevas de Vera, era tres años mayor que Victoria y había empezado antes que ella a cultivar amistades con aquellos círculos que entrelazaban al beau monde con la bohemia artística e intelectual en París. Allí mantuvo una vida social muy intensa, de la que Victoria heredaría muchas relaciones, como por ejemplo el grupo de españolas de avanzada que se reunían alrededor de la duquesa de Dato, mecenas de Miró, y Eugenia Errázuriz, amiga íntima y mecenas de Picasso, a quien 
Tota había conocido en Biarritz. Tota fue retratada por Hermenegildo Anglada Camarasa y descripta en Souvenirs du gentilhomme de Jean-Louis de Faucigny-Lucinge como "inteligente y muy bas-bleu" ${ }^{\text {"2 }}$. Frecuentó a los surrealistas, en especial a Luis Buñuel, con quien mantuvo una amitié amoureuse. Tuvo también un intenso romance con René Crevel, poeta, comunista, dandi y esnob al que conoció en una soirée en casa de Marie Laurencin (cuando está internado, Tota le lleva al hospital, para que se entretenga, las obras completas de $\left.\mathrm{Marx}^{83}\right)$. A diferencia de Victoria, Tota era libertina y amiga del escándalo : cuentan que en Buenos Aires le robaba la ropa a su mucama para irse a intimar con los marineros del Dock Sud ${ }^{84}$-algo que Gombrowicz hubiera probablemente apreciado, tener como precursora en esos rincones del bajo mundo a una condesa argentina. Fue una exponente de las llamadas "duquesas rojas", nobles seducidas por el estalinismo que abrazaron la gauche divine, "comunismo rococó o bolchevismo de salón"85. Lo mismo Delia del Carril, discípula de Ferdinand Léger en París : "era el esnobismo al revés de pertenecer a la élite de la antiélite" ${ }^{\$ 86}$. Si bien tenían una relación competitiva ${ }^{87}$, la influencia y los contactos de Tota Cuevas marcaron a fuego la construcción estética de Victoria; esto puede verse en la ropa, en la decoración, y sobre todo en la imagen de la mujer moderna que eligió forjar (es Tota, por ejemplo, quien le regala el tapiz de Picasso que Ocampo había puesto de alfombra y luego cuelga en Villa Ocampo para salvarlo de los cigarrillos que sus invitados tiraban al piso ${ }^{88}$ ). La joven Victoria no cedió, sin embargo, a las fascinaciones surrealistas de su amiga, siempre tan à la page, y como buena criolla, reacia a lo sorprendente, mantuvo una distancia irónica respecto del grupo de amigos de Breton que encandilaron a la condesa de Cuevas -Victoria juzgó probablemente "esnob", en sentido peyorativo, este interés de Tota por lo último, lo nuevo y lo original, ella que tenía una concepción personal de la historia y cultivaba un trato íntimo con la tradición que la llevó a querer siempre innovar, pero nunca destruir. Probablemente, desde su perspectiva, querer "épater" trasluciera cierta vulgaridad y querer destruir fuera casi una grosería (ya decía al comienzo de su autobiografía, al hablar de sus antepasados, "ni vengarlos ni seguirlos : continuarlos a nuestra manera, que no puede ser la de ellos" ${ }^{89}$ ). Tampoco compartió la pasión que su amiga tenía por las artes visuales, que la acercaron a pintores como Dalí y Miró. Que la capacidad de selección de Ocampo era implacable, es bien sabido ('En mi vida sólo he sabido 'preferir' con violencia. Para mí las cosas que no son 'preferidas' se obliteran" ${ }^{90}$, decía ya en 1935), y así como dejó de lado a los surrealistas y no se invistió en el coleccionismo de arte, sí se preocupó por ocupar todos aquellos otros terrenos que coincidían con sus preferencias. En este sentido, puede decirse que el desarrollo de Tota Cuevas en el mundo intelectual y mundano de París sedimentó la tierra que Victoria venía a sembrar -y que luego, para su gran decepción, no iba a poder cosechar. Tota ofició de go-between entre su amiga y las grandes personalidades de la modernidad europea : le presentó a Le Corbusier, a Mary MacCarthy y al grupo de The Partisan Review, a Marie-Laure de Noailles, muchos de los cuales había ella misma conocido a través de Eugenia Errazuriz, como Jean-Michel Frank, primo de Ana Frank (dato insólito) y decorador de interiores con quien la distinguida chilena revolucionó el estilo y los muebles de las grandes casas europeas (sus diseños, por otra parte, se vendían también en Comte $^{91}$ ). Suerte de soldado desconocido de la historia del gusto en Argentina, "Tota, como buena taste-maker, borró sus huellas"92.

24 Lo mismo puede decirse de Eugenia Errazuriz, "árbitro de todas las elegancias", a quien Victoria conoce también a través de Tota, y a quien le dedica un artículo en Soledad Sonora . Eugenia era treinta años más grande que las dos argentinas -madrina de Carlos Morla Lynch, en sus memorias se refiere a su influencia como a un hechizo- y había sido amiga 
de la madre de Tota, María Teresa Llavallol Elía de Atucha. Había sido, de joven, una belleza que deslumbraba en Londres (llegó a retratarla Boldini, y no Helleu, el pintor de segunda línea por el que pasaron Victoria y tantas otras niñas bien, siguiendo el ritual gregario de su clase ${ }^{93}$ ) ; de vieja se convirtió en una figura legendaria del buen gusto. A su villa en Biarritz, "La Mimoseraie", concurría mucha gente del mundo artístico y de la alta sociedad ; allí pasan los primeros días de su luna de miel Picasso y Olga Khokhlova en 1918 ${ }^{94}$, el mismo año en que Proust, por otro lado, la visita en su departamento de la Avenida Montaigne (encuentro que no podía sino acuñar su entrada segura en La Recherche, donde aparece evocando un tipo de mujer, un estilo de vida y un departamento lleno de pinturas cubistas ${ }^{95}$ ). Eugenia fue la primera en vaciar las casas del rancio prestigio de los muebles antiguos, la primera en encontrar en el despojo una estética elegante -llega incluso a raspar (décaper) las firmas de las sillas y las mesas que tenía del siglo XVIII. Jean-Michel Frank dijo alguna vez que todo lo que sabía lo había aprendido de ella, él que siguiendo su ojo avizor había creado su famoso estilo "luxe pauvre" (que Mauriac llama "ruineuse pauvreté" y Cocteau, al entrar en el departamento de Frank en París, resume con una de sus clásicas ocurrencias: "Dommage qu'il soit cambriolé !" Victoria al respecto, que veía en el estilo de Eugenia la marca de un cambio de era del que se sentía parte- y estoy contenta de haber nacido en la época del 'cambriolage' de las casas"97). Eugenia había sido amiga de Alfonso XIII y de los condes de Beaumont, y lo fue también de Izaak Rubinstein (padre de Arthur, de quien será mecenas), de Blaise Cendrars (que dio la primera pista acerca de sus orígenes bolivianos ${ }^{98}$ ), de Max Ernst, de Dalí, de Le Corbusier, de Jean Cocteau, de Man Ray, de Giacometti, de Chanel, de Stravinsky; de Picasso es de las primeras en percibir el genio. Toda esta gente le presenta Eugenia a Tota y luego Tota a Victoria (menos a Man Ray, que Ocampo conoce a través de Benjamin Fondane).

Estas mujeres fueron inquietas y no menos tenaces. A pesar de los prejuicios que no hubiera podido evitar una empresa cultural enteramente manejada por mujeres ricas, "Amigos del arte" fue una asociación moderna, abierta a la vanguardia y a la diversidad: trajo a conferencistas como Le Corbusier y Federico García Lorca, organizó el primer Cine Club del país (donde se proyectó, antes de su estreno en España, El perro andaluz de Buñuel), promovió conciertos de tango y de jazz, hizo muestras como nunca antes se habían hecho en Argentina, retrospectivas dedicadas a artistas decimonónicos y exposiciones de arte contemporáneo -en 1931, por ejemplo, aparecen expuestas obras de Antonio Berni ${ }^{99}$. Pueden incluso encontrarse menciones a "Amigos del Arte" en las páginas de la revista de extrema izquierda Inicial ${ }^{100}$ : en el número 7 de diciembre de 1924, por ejemplo, se anuncia un recital de poesía organizado por la revista y auspiciado por dicha asociación en el que "la señorita Mony Hermelo" recitará poemas de Silva Valdés, Arrieta, Juana de Ibarbourou, Hector M. Irusta, Ricardo E. Molinari, Córdova Iturburu, Capdevila y otros ${ }^{101}$.

La gestión de estas mujeres fue decisiva para el desarrollo cultural del país (su influencia llega hasta los años 60, si pensamos en personajes como Jorge Romero Brest, que monta el Centro de Artes Visuales del Instituto Di Tella con la experiencia del Cine Club, del que formaba parte, en mente). El silencio y el olvido, no obstante, fueron los únicos atributos que les legó la posteridad. Ya lo decía Rubén Darío en 1906: si para "el escritor blasonado" (cuya versión en los países latinoamericanos, aclara, es la del "rico autor") era difícil la vocación literaria (ven su obra como "labor de dilletante, como ocio de aficionado"), para la mujer todo era aún peor : 
En cuanto á la dama, á la mujer de alcurnia, que se atreve tales empresas, las dificultades suelen ser mayores. La sostenida inferioridad ancestral, la ligereza, las preocupaciones mundanas, la maledicencia, la social inveterada hipocresía, el flirt moderno, las atenciones de la moda, las influencias religiosas y la agresividad intelectual masculina se presentan ante las tentativas de una vocación. Se necesita ser una voluntad, un carácter, para oponerse á todo eso, para luchar, para vencer. ${ }^{102}$ Noailles -lo que implicaba argumentar que se podía ser al mismo tiempo mujer noble y poeta digna- Darío no tarda en oponerle a esta figura positiva de "dama letrada" todas aquellas otras figuras posibles (y plebeyas) que por supuesto denuesta como quien desprecia aquello que teme : "la literata", "la marisabidilla", "la cultilatiniparla". Ataca a "las preciosas" de Molière, aunque las prefiere a "la marimacho" $\mathrm{y}$, sobre todo, a "la snob, la decadente, la wagnerista, la partidaria del amor libre, la Eva nueva, la doctora escandinava ibseniana y la estudiante rusa que tira balazos." ${ }^{103}$ Entre la militante y la docta, es la esnob la que más fustiga en la lista de condenadas. Casi podría decirse que el adjetivo "esnob" resulta notablemente práctico a la hora de deslegitimar a una mujer dispuesta a hacer "cosas de hombres" como podían serlo leer, escribir y publicar.

No sorprende, en consecuencia, dada la época y el personaje, que la sociedad argentina haya reducido desde el mismísimo principio a Victoria Ocampo al estereotipo de "la esnob". Ella misma lo sabe e incluso juega con aquel ineludible punto de partida : "No se sabrá en qué canasto meterme, y se acabará por arrojarme sin rodeos al canasto [de los esnobs]" "104, escribe en 1927. En el número de homenaje en vida que le organizan en 1962 ${ }^{105}$, el historiador José Luis Romero parece entender este fenómeno mejor que muchos de sus contemporáneos: "Casi nadie se lo dijo nunca, quizá porque no era propio de snobs decirlo; pero ella no tenía nada de snob, sino el pecado de ser su paradigma" ${ }^{106}$. Esnobismo y género aparecen unidos en la misoginia compartida por los hombres de principio de siglo ; valga de ejemplo una cita de un artículo que Leónidas Barletta publica en Claridad el 10 de julio de 1927 :

Que Ansermet se deja influenciar por las mujeres lo evidencia el hecho de que son sus admiradoras, con Victoria Ocampo a la cabeza, las que costean la temporada para mujeres y maricas que va a dirigir en un cine-teatro de la aristocracia [...]. Y mientras Victoria Ocampo, envolviendo su elegante silueta en un vestido de 'chifon' rojo con 'drapeados' y franjas 'aigrettes' sobre 'lamé' plateado aplicados con 'estrás', recite con voz llena de exquisitas inflexiones los parlamentos de 'Roi David' bajo la batuta paternal del maestro de las barbas floridas, desfallecerán en sus butacas las neuróticas niñas. ${ }^{107}$

No sólo publicaciones políticas de marcado corte ideológico como Inicial incurren en este tipo de prejuicios. El uso del término "esnob" por parte de discursos machistas es un lugar común de la época, incluso en revistas cosmopolitas y mundanas como la cubana Parisina. Espejo de las elegancias parisienses, publicada por C. D. de Battemberg en español desde París entre 1926 y 1928, una suerte de ${ }_{j} H O L A$ ! con ribetes intelectuales en la que colaboran escritores como Enrique Gómez Carrillo y Alfonso Reyes. En 1928, en la sección "Vida parisiense", se anuncia la apertura de un nuevo salón literario en París, esta vez por un Ministro de Instrucción Pública, el señor Edouard Herriot (y su mujer), al que acuden figuras como el pintor japonés Fujita y el escritor francés Paul Morand; este hecho se celebra vivamente ya que "lo que se diga en casa de un ministro tiene más resonancia que lo que se murmure, sobre los mismos personajes, en el salón de una dama snob que nadie toma en cuenta si no fueran sus buenos cocktails"108. Los ministros dicen pero las esnobs murmuran, salvo, claro está, cuando se ponen a hacer ruido. En otro número, al comentar 
el divorcio de Fujita, se describe a la tercera en discordia como "una parisiense muy bella, muy bulliciosa, muy snob" cuyos "caprichos" ${ }^{109}$ escucha el pintor. El esnobismo se pliega así a todo tipo de carácter, siempre y cuando sea el de una mujer -y esto en una revista que le dedica un importante espacio a la moda femenina (en general artículos de Thérèse Clemenceau) y presenta retratos de mujeres de la alta sociedad en secciones como "Señoritas del gran mundo latinoamericano", "Elegancias de Buenos Aires", "Elegancias argentinas" (donde aparece la foto mencionada de Victoria Ocampo por Van Riel ${ }^{110}$ ), "Bellezas cubanas", "Damas del gran mundo", "Elegancias cubanas en Europa" o "Damas de la colonia latinoamericana de París". Queda establecido que si una mujer tiene un salón se convierte automáticamente una esnob que está en pose ("una dama que se entrega al encanto de la cultura con un escéptico diletantismo" ${ }^{111}$, se lee en la editorial del número 18) y si el "Tout Paris" se digna a concurrir es porque ofrece buen alcohol -quién hubiera podido imaginar, en este sentido, el éxito de SUR, proyecto de una presunta esnob cuyas reuniones habrían de ser siempre abstemias, a su imagen y semejanza ("una de sus extravagancias", dice Sábato, que recuerda cómo se servía en cambio un té "delicioso" y la angustia que sentía después de seis horas de tertulia a puro té, una angustia que no conmovía a la anfitriona -"Victoria era tan despiadada como un mormón o una anabaptista"- y lo obligaba a "despedirse y salir de estampida para irse a tomar un whisky en la esquina, igual que un vicioso"112).

\title{
Una colección de grandes hombres
}

\author{
"To be oneself is not enough ; one must be \\ 'somebody"' \\ ARTHUR KOESTLER, "An essay on snobbery"
}

30 “¿Todos sus amigos son escritores ?”, le pregunta la joven periodista de Atlántida a una Ocampo octogenaria y un poco sorprendida por la frescura de su entrevistadora ("no basta cierto número de años para estar gagá, ni la juventud para tener ingenio"113, dirá luego al respecto). La pregunta, ingenua o irónica, apunta a señalar un aspecto del mentado esnobismo de la directora de SUR: su red internacional de amigos célebres. A fines de los 60, Ocampo sigue siendo conocida por su proximidad con aquellos grandes nombres de la literatura. La curiosidad que estas relaciones despiertan parece infalible; no otra cosa frustraba a Adelaida Gigli :

Creemos que debe poseer pormenores fatales al contacto increíble de esas vidas, la dolorosa observación personal, la duda, el secreto personal. Pero calla : no sé si por avaricia, piedad o vergüenza. Quizá para anonadarnos un día con algún diario desnudo y aterrador. Pero ahora nos estafa, ¿qué clase de testimonios son éstos ? ${ }^{114}$

"El contacto increíble de esas vidas": lo que asombra no son esas vidas extranjeras y célebres, sino la posibilidad de tener un contacto con ellas. Incluso entendida como una hipálage, el énfasis cae sobre el carácter inalcanzable de aquellos "otros", y resalta así la excepcional circunstancia de poder codearse con ellos. Es importante no perder de vista que, en este razonamiento en particular, la perspectiva de Gigli es clave; como lo dice Epstein: "Status is not in the possession of its holder but in that of the beholder"115. Que Ocampo sea amiga de tanta gente famosa sorprende e intriga tanto a Gigli como a la joven periodista de Atlántida -y lo mismo le pasaría, intensa o fugazmente, a cualquiera que lea su nombre en semejante dulce montón. Sería raro pensar que Victoria Ocampo no supiera cómo funcionaba esta dinámica particular del esnobismo social ; más bien, podría decirse que la manejaba con maestría. Pero para comprender con precisión en qué consistió su 
destreza es importante distinguir en su obra y en su gestión diferentes prácticas y usos del esnobismo social. En primer lugar, diferenciar algo que podríamos llamar "cholulismo de ocasión" de lo que fue su culto al héroe. En segundo lugar, especificar el doble uso que hizo de las relaciones públicas : por un lado, en la construcción de una red personal a través de la cual forjó un estilo de vida y de figura; por el otro, en el desarrollo de su proyecto cultural, SUR, para el cual capitalizó el esnobismo del otro (el de Gigli, por ejemplo) usándolo como el gancho de una intriga capaz de atraer y formar un público nuevo. Si bien fue medida y rigurosa en este uso, (no impostó jamás gustos falsos y evitó siempre la ostentación vacua) ${ }^{116}$, Ocampo descubrió, quizá, que no sólo los esnobs sino también los cholulos podían ser funcionales a su obsesivo y serio anhelo de formar una élite futura de mentes fraternas -“mientras, un joven fino del centro de Buenos Aires, regresando de un té en casa de Victoria Ocampo, lleva bajo el brazo una revue parisina y un poema chino ilustrado con dibujos"117, escribe Gombrowicz en 1959.

\section{¿Cholula o fanática?}

Vale la pena detenerse brevemente sobre un aspecto particular del esnobismo social que Arthur Koestler llamó "complejo de Crillon". La explicación del nombre es anecdótica ; el sentido, en cambio, un fenómeno universal. Louis des Balbes de Berton de Crillon fue un soldado francés conocido por la misiva que le envía el rey Enrique IV después de haber ganado la batalla de Arques en 1589 : "Pends-toi, brave Crillon! Nous avons combattu à Arques, et tu n'y étais pas”. El monarca lo burla como quien burla a un amigo : qué picardía, le dice, sos el mejor soldado del reino y te venís a perder justo el triunfo más memorable (algo así como ser Messi y no estar en el partido que se llevara por fin la copa del mundo). De esta anécdota, Koestler desprende una reflexión sobre el cruce que se da entre el deseo frívolo de conocer gente famosa y el impulso atávico de querer formar parte de la historia ("the urge to participate in, or at least be present at, the making of history"). A la pregunta de por qué a la gente le gusta conocer gente famosa, el escritor húngaro-británico propone tres posibles razones: la vanidad social ("I have met the famous X"), una genuina curiosidad de saber cómo son esas personas en la vida real o, menos superficial que la primera y más común que la segunda, "el complejo de Crillon" :

But the millions who used to flock to White House to shake the President's hand, before that custom was abolished, were driven not so much by vanity or curiosity as by the desire to "shake hands with history." The crowds who go to any length of trouble to catch a glimpse of a coronation, or a visiting statesman, or the eruption of a volcano, are at least partly motivated by the desire to "have been present," to "witness history in the making," to participate, in whatever passive or remote manner, in the world-shaping events of one's time. The reverse of this urge is the fear of "missing something," of failing to exploit to the full the chance of being a contemporary, a witness of one's time. ${ }^{118}$

Esto es lo que percibe Gigli, que Ocampo es, tal como se presenta en sus escritos, un testigo presencial de la historia que ella lee en los libros, diarios y revistas o escucha por radio y televisión: "es la dama duende de esferas más altas, que espía a esos que jamás conoceremos, a los que jamás tenderemos la mano"119. Es decir, al hacer un juicio implícito sobre el esnobismo de Ocampo (le reprocha una ostentación de relaciones mundanas que no crea valor literario, además de ser avara con los chismes), Gigli proyecta sobre ella su propio complejo de Crillon : ¿cómo se da la mano con la historia y no nos cuenta nada? No lo puede entender. jQué estafa!, juzga. 

reside en la concepción que Ocampo tenía de la historia. Era muy personal. Había nacido no sólo "in the making" de la Argentina sino en el mismo seno de ese "making": descendiente directa y cercana en el tiempo de una familia fundadora, eligió interpretar su genealogía como un oráculo cuyos designios, sin embargo, ella misma se ocupó de guiar. Reconstruyó en sus escritos su árbol de familia como quien traza un destino ; la escritura se habría vuelto no sólo inevitable sino necesaria cuando entendió que no alcanzaba con nacer para heredar; que no se nace heredero, se llega a serlo. Eligió de entre sus ancestros a aquellos que quería que la representasen ; con los próceres, hizo lo mismo $^{120}$. Asoció estas preferencias a escenas y objetos de su infancia, a lecturas, animales, olores, lugares y músicas de cuando era chica; fueron asociaciones que estableció de una vez y para siempre, y que repitió con pequeñas variaciones a lo largo de su obra. Nunca se cansó. Tejió así, con los signos del mundo que prefirió y devoró, un pequeño sistema de verdades sobre ella misma, un sistema frágilmente sostenido afuera de ella, en aquellas combinaciones íntimas y sempiternas que cifraba a su alrededor ${ }^{121}$. En Sarmiento vio a un padre espiritual y en su linaje patricio el llamado a una misión que había cambiado de signo ; escuchó ese llamado con el mismo fervor con el que Juana de Arco había respondido a la voz de Dios ${ }^{122}$. La guerra de la independencia ganada, era ahora el turno de dar la batalla cultural. Desde esta perspectiva, darle la mano al presidente Charles de Gaulle no podía ser un mero azar. No estaba ahí, en el Eliseo, de manera anónima; almorzaba a su lado, tenía su tête-à-tête (De Gaulle le pregunta por Frondizi, hablan de Perón). Lo más probable es que Ocampo no viviera estos encuentros con la exaltación de quien recibe un privilegio extraordinario sino con el sosiego del que corrobora un derecho divino. No, probablemente Victoria Ocampo no tuviera un complejo de Crillon, lo que no significa que no fuera a contarle a sus hermanas y amigos si se cruzaba a un famoso en uno de sus viajes (la causa superficial que mencionaba Koestler) o que no sintiera la urgencia genuina de conocer a aquellos escritores que había leído con pasión (la causa atípica que señalaba Koestler).

Ocampo tuvo, por un lado, impulsos "cholulos"123 (consigue, vía Waldo Frank, una foto autografiada de Charles Chaplin; cuando ve a Lya de Putti en un barco le escribe a su familia que es "terriblemente made in Germany" ${ }^{24}$; cuando ve a Rita Hayworth en una disquería de Madison Avenue le comenta a Angélica "es muy bonita pero parece una shop girl cualquiera (si no fuese por el mink)"125 ; organiza un almuerzo en Villa Ocampo para Vivien Leigh para poder fotografiarse con ella ${ }^{126}$ (un año antes había estado allí Helen Hayes); en Nueva York consigue desviar el trago que le propone un embajador ecuatoriano hacia un comedor en donde canta Frank Sinatra, "basking en ese sol [la adoración del público] como un lagarto"127). En la misma línea, no pierde oportunidad de comentar con sus hermanas Angélica y Pancha los chismes que se va enterando de la familia real (que la reina toma píldoras para aguantarse el pis en ceremonias largas o que los almohadones amarillos del sillón de los Windsor llevan el lema "never complain, never explain"128) o de la familia presidencial americana (que la hermana de Jackie Kennedy, hospedada en el Ritz, habla todos los días por teléfono con su hermana; "es pretenciosa (Jackie no)" ${ }^{129}$, sentencia Ocampo). Por el otro, en la vereda opuesta de aquellas "pavadas" ("bueno, basta de pavadas", escribe en sus cartas), fue devota de santos laicos que no eligió al azar, entre los cuales T. E. Lawrence es el mejor ejemplo ${ }^{130}$. En el primer caso, evoca someramente a aquellas chicas que formarían en los 60 el club de Cazadoras de Autógrafos de la Argentina, obreras de mañana y aprendices por la tarde 
que al final de la jornada se evadían de la realidad esperando a Mirtha Legrand a la salida de la radio Splendid con una birome en una mano y el álbum de autógrafos en la otra. En el segundo, sobrepasa el entusiasmo de una fan convirtiéndose en una creyente seria, fervorosa y ascética. Agreguemos una tercera modalidad, más errática y bastante más común, seguramente, de lo que uno imaginaría : cuando acercarse a aquel "otro" de nombre conocido responde a una curiosidad o a una rivalidad del orden de lo íntimo. Es el caso de Jacques Lacan, que había comenzado una relación amorosa con Olesia Sienkiewicz cuando ésta todavía estaba casada con Drieu la Rochelle. Ocampo, que ha empezado a frecuentar a este último, busca conocer al joven psicoanalista porque, según reporta Elisabeth Roudinesco en la biografía que hace de él, "era el amantito de la mujer de Drieu" 131.

La diferencia entre Gigli y Ocampo, para concluir esta idea, es como la que hay entre el álbum de una de aquellas cazadoras de autógrafos (dejando de lado la diferencia que hay entre escritores legendarios y actrices de radionovelas locales) y el que conforman las firmas que marcan las primeras hojas de la biblioteca de Victoria Ocampo ; el primero es una colección de firmas imaginarias, el segundo una de pertenencias. Estas dedicatorias ya no son los testigos de una evasión, sino los de la construcción de una realidad. Ocampo no "caza" esos autógrafos; los recibe como ofrendas dedicadas en su honor. A través de estos, al mismo tiempo, modela su excepcionalidad: llevan el puño y letra de Paulhan, Valéry, Camus, Malraux ; la lista es larga. Lacan, por ejemplo, le dedica cuatro libros, el primero en 1933 (“À Victoria, cette œuvre qui n'est qu'une première pierre, mais que j'aimerais qu'elle accueille dans son jardin”), el segundo en 1966 (“A Victoria, mujer de este siglo, única"), y el tercero y el cuarto -que son el mismo y cuyas dedicatorias llevan la misma fecha- en 1975 (en uno pone "Quelle drôle de chance qu'on se retrouve aujourd'hui, Victoria" y en el otro "Victoria, mon amour... Je t'envoie ça"). La más linda de todas estas dedicatorias sea probablemente también la más íntima, de Drieu La Rochelle : "À Victoria Ocampo, à Vénus et Marie"132.

37 La cuestión, por otra parte, de la aventura sexual con el hombre célebre, Koestler la trató como un aspecto específico del complejo de Crillon y la ilustró con el caso de "Mary B.", una amiga suya que sólo podía acostarse con escritores que hubieran vendido más de 20,000 copias. Por problemas de índole religiosos o edípicos, no es claro, a Mary le era imposible sentir placer sexual con hombres jóvenes de su edad, pero cuando se acostó por primera vez con un escritor mayor y conocido se dio cuenta de que, en aquel caso, el acto se justificaba por ser en sí mismo una incursión en la historia, un acontecimiento que le permitía a la vez explorar su sexualidad y decirle a su padre :

But you see, Papa, having an affair with a famous man is not frivolous -it is like going to bed with History. Who would blame Marie Walewska for surrendering to Napoleon? Everything you do with a famous man is redeemed from its sinfulness by becoming a Historical Anecdote. ${ }^{133}$

Un chiste similar pero más extremo, que lleva esta lógica al absurdo, aparece en Girls, la serie americana de $\mathrm{HBO}$, cuando una profesora universitaria que entrevista a Hannah (la protagonista) le da a entender que tuvo una aventura con un escritor famoso. "You know who Norman Mailer is?", le pregunta a Hannah, que responde excitada : "Yeah, Norman Mailer!"; "he had a friend named Jeff who was fucking crazy for me" ${ }^{134}$, concluye la primera. Victoria Ocampo conocía los réditos que una mujer podía sacar con el sólo hecho de acostarse con hombres célebres, y los despreciaba (sin ir más lejos, si bien reconoce el talento de Simone de Beauvoir, no le perdona el "esprit faux" ni el "complejo de superioridad por haberse acostado con el inteligentísimo y físicamente repelente autor de 
Huis Clos [sic], durante varios años"135). En sus entusiasmos literarios era, más que una estratega, una mujer crédula, aunque puede argumentarse que no necesitaba acostarse con esos autores que buscaba conocer para conseguir explotar dicho vínculo. El episodio con el conde Keyserling, que comentó largamente y al que le dedicó incluso un libro implacable ${ }^{136}$, es suficiente prueba tanto del imperativo moral que la fundaba como de lo creativos que podían ser los recursos que desplegaba para afirmarlo -sobre todo si imaginamos que, con tal de hacer respetar su derecho a entusiasmarse con un escritor sin tener por ello que acostarse con él, llegó a tirarle al conde alemán una plancha por la cabeza $^{137}$.

\section{"2 o 3 [esnobs] para el uso personal"} estaba ya en la intención del viaje; cuando zarpa el barco, zarpa con él también el comienzo de su misión patricia. Victoria no es ingenua al respecto. En la correspondencia con su hermana, aparece la noción de uso asociada a la frecuentación mundano-literaria. Entre febrero y marzo de 1930, escribe :

Anoche vinieron aquí Drieu, Isabel Dato, Delia [del Carril] y [Manuel Ángeles] Ortiz. No creas que toda esta gente es siempre muy divertida, pero mientras que uno no los conozca interesan, y cuando uno los conoce se queda con 2 o 3 para el uso personal y los demás "on les laisse tomber". ${ }^{138}$

Lacan es muy extraordinariamente inteligente, pero de carácter intolerable -peor que Drieu a pesar de ser totalmente distinto- Nos peleamos diariamente y a cada rato tomo la resolución de no verlo más. Pero como no tiene reemplazante que se le asemeje, lo sigo viendo. ${ }^{139}$

Fue, no obstante, un uso con discernimiento: Ocampo no fue una esnob omnívora. Cuando come con Léon-Paul Fargue en lo de Josefina de Atucha, anota "(divertido pero me revienta)"140. El salón de moda de Marie-Louise Bousquet (que en 1937 sería la editora de Harper's Bazaar francesa), al que asiste, le parece "un opio, en resumidas cuentas" ${ }^{141}$. El ballet de Poulenc "no [le] resultó gran cosa" ${ }^{42}$; la obra de teatro de Cocteau "no [le] gusta... NADA" ${ }^{143}$. Recordemos, a propósito de esta última, que en el segundo ensayo general de La Voix Humaine se armó un pequeño escándalo que fascinó al público de amigos y conocidos, pero no a Ocampo, a quien este tipo de revuelos dejó bastante indiferente (el surrealista Paul Éluard se había parado e insultado la obra, al director y a su amante al grito de "obscène ! obscène !" ; -Jean Hugo anotará después "Jean [Cocteau] est enchanté. Il a eu son scandale" ${ }^{144}$ ). Victoria solía comer con la pareja de Cocteau y Desbordes ; también con Ramón Gómez de la Serna, George-Henri Rivière, Fargue, Drieu y otros. Cada día de ese viaje tiene sus obligaciones y responsabilidades : “Ce soir j'ai à dîner avec Ortega, Drieu et Leo Ferrero. C'est à dire que ce soir sera Ortega qui tombera dans le monologue. Dimanche ce sera Fargue et lundi Cocteau." ${ }^{145} \mathrm{Si}$ bien estas nuevas amistades le resultan muchas veces insoportables, no dejan por eso de divertirla : "Mais comment faire pour quitter Paris et même ces gens que je déteste? Ils m'amusent!" ${ }^{146}$. En este sentido, es consciente de las limitaciones que puede tener el encanto de estos personajes, como Anna de Noailles, pero también del aporte que traen a su vida aquellas mentes vistosas, de réplica rápida e ingenio culto : “Tout ça c'est de gens 'à change favorable'... C'est à dire que j'ai l'impression (pour Anna surtout) que leur facilité d'expression verbale est plus éclatante que la qualité de leur pensé. C'est, d'ailleurs, merveilleux de les entendre." ${ }^{147}$ 
Ocampo ya había delineado, tres años antes, una definición similar, a saber, la de alguien un poco frívolo o un poco ridículo, pero divertido y funcional, no obstante, a los avances estéticos de la modernidad. En 1927, año en que el aniversario de la muerte de Beethoven desató una polémica que puso en el centro a los esnobs, Ocampo había decidido intervenir en el debate y lo había hecho a través de una mise en scène que publica en La Nación. Simuló, así, haber recibido una carta de un desconocido (que ella misma escribió y publicó con nombre falso) y haberse sentado, en enero y con treinta y pico grados de calor, a responderle (cosa que hizo, es decir, responderle a su propio homme de paille y publicar luego ambas cartas como una "correspondencia"148).

La epístola ficticia contenía un grito de auxilio que, desafiando las lentitudes de la canícula, la había obligado al esfuerzo de una reacción rápida : el tal "señor X” tenía una urgencia frívola y estaba desesperado. Había leído en La Nación el artículo "Arte y moda" del musicólogo Ernesto de la Guardia (también autor de "Nuevas reflexiones sobre el snobismo") y parecía estar recién despertándose a los nuevos peligros de la época. Su situación era compleja : prefería, como ella, el Concertino de Honegger a la Quinta Sinfonía de Beethoven, y se alarmaba frente al riesgo de ser etiquetados, ambos, "snobs".

A este respecto, vale la pena recordar que el mentado Concertino produjo, de hecho, una silbatina que muchos diarios y revistas comentaron, un espectáculo memorable en el que unos aplaudían y otros silbaban (lo que evocó en Ocampo, por supuesto, la experiencia de Le Sacre du printemps de $1913^{149}$ ). Mientras Barletta escribía enfurecido desde Claridad sentencias del tipo "es inadmisible que eso se mezcle con la buena música" o "la de Honegger es evidentemente música para maricones" ${ }^{150}$, Ocampo celebraba que una escena así pudiese tener lugar en Buenos Aires. Encantada con la silbatina como lo estaría después Cocteau con los insultos de Éluard, juzgó que la división del público del Concertino era un signo de salud cultural en el país : silbar era de hecho -dice no sin sorna- "muy chic y se lleva mucho en París"; por otra parte, añade, "los snobs se sienten muy importantes con aplaudir cuando otros silban." ${ }^{151}$

Están los que aplauden por gusto (Ocampo), los que aplauden sin entender nada (el esnob) $\mathrm{y}$ los que silban (Barletta). Para el señor X, perteneciente al primer grupo, que lo confundan con el segundo le parece gravísimo -y no porque los esnobs le parezcan una plaga absolutamente indeseada ; por el contrario, a pesar de encontrarlos "exasperantes y ridículos", valora su aporte a la renovación de la cultura (aplauden sin entender las obras novísimas que dirige Ansermet, por ejemplo, en lugar de silbarlas como salvajes) y hasta se extasía imaginándolos "ricos y generosos" (si todos fueran así, "sería menester prohibirles que abandonaran el país", sueña despierto el señor X bajo la pluma de Ocampo, como alguna vez soñó Alberdi con obreros británicos poblando el suelo argentino). No le molestaban, entonces, los esnobs en sí mismos -su existencia, que estuvieran en las plateas de los teatros y en las librerías- sino que alguien pudiera confundirlo a él con uno de ellos. ¿Cómo diferenciarse acaso de aquel al que le gustaba "lo nuevo por ser nuevo" y respetaba "lo viejo por ser viejo", del que aplaudía el Concertino a pesar de haberlo padecido y compraba libros viejos en París sólo porque los libreros les decían que eran ediciones de "tiraje limitado"152? ¿Qué hacer con el problema del gusto genuino y el gusto impostado, ese callejón sin salida entre la autenticidad y la pose? Ocampo y el señor $\mathrm{X}$, aquel primer y único homme de paille que aparece en su obra, sabían que "estar al día", es decir, adoptar un gusto como se adopta una moda, no podía llevar a buen término: "tened cuidado. ¡Un día pasa pronto!"153, dice Stravinsky en un artículo sobre Beethoven que SUR publica en 1936. Para ellos, no era una cuestión de modas sino 
de espíritus. No había modas para los espíritus modernos, sólo preferencias certeras, distinguidas $\mathrm{y}$, sobre todo, naturales. El buen gusto aparece aquí como una inclinación espiritual ; poseerlo, sin embargo, podía ser muy peligroso -"está usted perdida", exclama el señor X, imaginando quizá una suerte de Mazorca anti-esnob, incapaz de leer matices que vendría a meterlos a él y a ella -espíritus exquisitos- "en el canasto de los snobs". “¡Venga usted en mi auxilio !", la exhorta a intervenir. ¿Pero qué le (se) responde ella ? La cita es conocida :

¿Por qué quiere usted que trate de convencer a este señor [de la Guardia] que no nos meta a usted y a mí en el canasto de los snobs ? Sospecho que ese canasto debe ser muy entretenido, y me encantaría pasar en él un week-end..$^{154}$

¡Qué importa lo que digan los demás! Esa es la postura de Ocampo, que enfatiza al final de su carta con una cita de Valéry en español : "toda crítica, toda censura, equivale a decir : yo no soy tú" ${ }^{155}$. Consigue, a través de la indignación del ficticio señor $\mathrm{X}$, mostrarse ligera y más allá. Socrática y maquiavélica a la vez, se sirve del clamor impostado de un hombre que parece ser de su misma clase, que tiene sus mismos gustos y que muchos confundirían con ella, para matizar y refinar su propia postura frente al riesgo inevitable de que la banalicen con el mote de frívola. Ocampo, contestándole a otros a través de él, se divierte con el tema. Donde él ve inquietantes malones de esnobs, ella ve una secta entretenida que en nada puede amenazarla; ¿qué puede importarle lo que digan de ella haters ignotos? Sabe de antemano que van a confundirla con una esnob, y "eso es precisamente lo que no debe preocuparnos, señor." Quizá la irrupción de los esnobs en el escenario cultural le sirviese también para distanciarse y diferenciarse de la mentalidad estrecha y rancia de su clase. "Qué lástima que no estés aquí, le escribe Victoria a Angélica desde Mar del Plata en 1933, ¡El comentario es indispensable para poder soportar el contacto de los grandes intelectuales!"156. En este caso se refiere a Waldo Frank, su amigo comunista al que acusa jocosamente de "negrero" por cómo les exige a ella y a Mallea que traduzcan su libro cuando los ve, al levantarse de la siesta, todavía sentados charlando en la sobremesa. Pero cuando, en esos días, va a comer a casa de sus tíos Diógenes y María Luisa Urquiza, los encuentra "completamente embotados en grasa y self-indulgence. El cerebro ya no funciona (si es que jamás funcionó)"157. La estupidez de sus parientes la lleva a escribir, pensando en Frank, "está bien que exista en comunismo"158. Varias veces habrá pensando lo mismo, como cuando sale en París con un grupo de argentinos y franceses de la alta sociedad : "Ayer almorcé en casa de Jovita con los Ganay, Philippe B y el conservador del Museo de Versailles. Esa gente de mundo, a fuerza de ser idiota, ni mundo tiene." ${ }^{159}$ Hubert Ganay, por ejemplo, comenta en dicho almuerzo cuántas ganas tiene de visitar el Hermitage en su próximo viaje a Rusia. Ocampo se indigna :

¡Ha habido una revolución que ha cambiado la vida de millones de personas !; que ha ébranlé el mundo entero. Y cuando va a visitar el país donde se produjo, sólo le inspiran curiosidad los objetos de un Museo [sic].

Con razón pasa lo que pasa con la gente de su especie. ${ }^{160}$

La indiferencia a la historia es una actitud que consigue enfurecerla. Lo mismo le ocurre durante la segunda guerra mundial con el grupo de Jean-Michel Frank, Gogo Schiaparelli, Coco Chanel y amigos, cuya frivolidad ${ }^{161}$ durante esos años la alarma a tal punto que sólo puede insultar: "Je dis: merde." 162 Sobre Frank en particular -de un esnobismo estilístico: "J. M. parle sans interruption, avec des incidents et des parenthèses à la Proust, appelant les gens de 'son milieu' par leurs prénoms et surnoms"-, llega a decir : "Quand on entend J. M., on se dit que ce les Allemands reprochent à la France (d'être un pays gouverné par Gogo et Coco) n'est pas sans fondements, hélas"163. 
zá la mejor prueba de que Ocampo no tuviera una actitud esnob per se y a priori, sino genuina y estratégica a la vez, sea el hecho de que, una vez que fracasa su proyecto cultural, una vez que SUR deja de ser lo que había sido en los 40 y los 50, y le cede su lugar, sin más opción, a las modas y valores nuevos de las décadas siguientes, ya no hay reunión, ni concierto, ni revista, ni encuentros que puedan satisfacerla. Aquellos esnobs en los que antes veía una cofradía divertida y de avanzada en el gusto, más tarde le parecen un puñado de tilingos. Incluso antes, hacia 1951, empieza a cansarse del juego de las relaciones públicas :

Cada día me siento más incapaz de conversar en almuerzos y comidas y cada día me repugna más la agitación mundanoliteraria. Sé que Roger [Caillois] (a quien le sucede lo contrario) ha estado en un cóctel en casa de (of all places) los Windsor. ${ }^{164}$

Con el mismo espíritu, doce años después, cuando la invitan a ver un espectáculo de Pierre Boulez en la Ópera de París, Ocampo escribe: "La sala llena de visones, perlas, brillantes y tilingos y tilingas." ${ }^{165}$ Más tarde, cuando el chofer de la embajada la lleva de

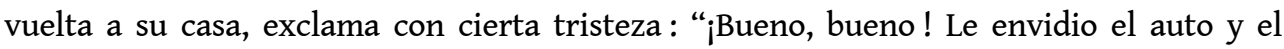
chauffeur... pero si es a precio de tilinguiar de mañana a noche..." ${ }^{166}$. Sin una misión patriótica por delante, el brillo se vuelve vulgar y vana la frecuentación de escritores y artistas. Así juzgaba, ya en 1951, la iniciativa del anfitrión de Caillois: "Parece que los Windsor invitaron a cierto grupo de escritores (los únicos de alguna significación eran Roger y Maurois) para faire mousser las tristes, opacas y nulas memorias del duque." ${ }^{167} \mathrm{Y}$ aquí volvemos a Gigli : a diferencia del duque inglés, Ocampo no buscaba salpimentar sus memorias ni "ser parte", tener roce con el mundo de la cultura; se sentía destinada a serlo (lo que quizá explica, por otra parte, por qué sus Testimonios no se volvían chismosos). Esto no significa, por otra parte, que no supiera que los demás, como Gigli y los futuros lectores de la biografía del duque de Windsor, iban a querer ser parte de esos mundos a través de ella.

\section{La empresaria mitológica}

No hay dudas de que Ocampo era consciente de la importancia que las relaciones públicas iban a tener en su trayectoria, sobre todo una vez que se decide a lanzar SUR. La idea de hacer una revista había sido originalmente de Waldo Frank, que soñaba con un comunismo fraterno que uniera a los hombres y mujeres del norte y del sur; amigo del editor de Babel, Samuel Glusberg (al que llama "dinámico inmigrante judío" en sus memorias), le propone a Victoria (a la que llama en cambio "princesa del buen gusto") financiar esta suerte de internacional comunista y compartir, junto a Glusberg, la dirección ${ }^{168}$. Su idea era también incorporar a José Carlos Mariátegui, que tenía la revista Mauta en Perú y acababa de perder una pierna, por lo que soñaba con venir a la Argentina tanto para realizar el proyecto de Frank como para encontrar una prótesis, él que tenía altas esperanzas puestas en la ortopedia argentina. Victoria parte a Europa en diciembre de 1929 con esta idea, y así la presenta cuando llega a Estados Unidos cerca de un año después ; usa, incluso, el título que había elegido Frank, "Our America” (es Ortega el que más tarde propondrá "Sur"). La idea de compartir la dirección, sin embargo, no la convence. El viaje le va a traer importantes experiencias y vínculos; entre ellos, una afianzada amistad con Alfonso Reyes, que va a alterar los planes de Frank. Reyes la alienta a fundar su propia revista, le dice que puede hacerlo incluso sin su amigo neoyorquino ; se perfila desde entonces la que iba a ser SUR. Mariátegui, por otro lado, muere en 1930, diluyendo la primera visión de Frank. En el viaje de vuelta a Argentina, Ocampo vuelve 
por el Pacífico; en el menú del barco hay dibujado un mapa del mundo sobre el que Victoria escribe a mano los nombres de las personas que quiere que colaboren de cada país. Esas firmas conformaban, ya en 1930, una red personal y un proyecto cultural. Asumir el rol social de una personalidad era necesario.

Figuras femeninas como la Princesa de Polignac ${ }^{169}$, Misia Sert, Lady Diana Cooper o Lady Ottoline no le eran ajenas. Ocampo sabía que de su papel dependía la posibilidad de SUR (ella había escrito el libreto): debía convertirse en el puente entre los puentes. Si los libros y los escritores eran los únicos capaces de unir las diferentes culturas del mundo, ella debía ser la ingeniera material (visionaria, embajadora y financista) que hiciera posible ese ida y vuelta. Si bien no articula explícitamente la importancia determinante de su "lobby", tampoco lo esconde cuando alude, en la mitad de un discurso, a intercambios de su correspondencia privada. En 1966, por ejemplo, año del trigésimo quinto aniversario de su revista, cita una carta suya a María de Maetzu donde le dice: "Para el asunto de Virginia Woolf hay que invocar el nombre de T. S. Eliot, con quien me vi en Londres" ${ }^{\prime 70}$. Es más, elige cuál es el libro de Woolf que va a publicar atendiendo a los consejos de sus amigos Aldous Huxley y Sylvia Beach : en 1936 hace traducir por Borges A Room of one's own, que no había sido todavía traducido al francés. Para la empresaria cultural, tener cintura mundana y saber figurar es parte de la descripción del trabajo. Este aspecto de su labor, por otra parte, le vale las críticas de algunos de los mejores diletantes de la época, como Borges y Bioy, y de iconoclastas como Gombrowicz. Los dos amigos porteños juzgan frívolas sus admiraciones literarias, la sospechan de ser demasiado sensible a la fama y la acusan de buscar en la literatura apenas una vidriera donde poder mostrarse :

Admiró a muchos escritores, totalmente disímiles desde luego, pero que tenían en común la fama o por lo menos la notoriedad: Tagore, Ortega, Keyserling, Waldo Frank, Camus y tantos otros. ${ }^{171}$

BORGES : Una vez, un señor le explicó a Pipina Diehl : 'Lo que a mí me interesa es figurar'. BIOY : ‘Un poco ingenuo pero se conoce mejor a sí mismo que Victoria, Aita y tantos otros'. ${ }^{172}$

51 La última cita es a propósito del PEN Club, celebrado en Mar del Plata en 1962, al que también asiste Gombrowicz (como público y no como invitado : “Cómo es que no me han invitado? Ese Aita, ¿quién es y qué ha escrito? (Nada)"173, escribe en su Diario). Witold disfruta del roce con escritores conocidos que empiezan a reconocerlo como uno de ellos (se sienta en los sillones al lado de Madariaga, Silone, Robbe-Grillet y Weidlé), lo que, como era de esperar, lo sume en la más terrible angustia :

¡Qué tormento! ¡Mi orgullo aúlla como un perro! Siento pánico y náuseas, porque me acomete y se apodera de mí aquello que yo tantas veces había despreciado; yo, un solitario orgulloso, enterrado vivo desde hace veintitrés años en Argentina. ¡Oh, estar demostrando con la vida entera que a uno no le importan los honores, mofarse de esta mondanité, ser incorrupto e inaccesible... para, de pronto, en la constelación de los cinco sillones, experimentar una admiración de lo más pequeño burguesa y sentir en sí el impulso que clama por ser admitido en esta sociedad, por ser uno de ellos !174

Ocampo también se angustiará en esta ocasión, pero sólo porque su invitación no le llega en tiempo y forma, aunque se entera después por los diarios de que sí ha sido invitada (el corto discurso que pronuncia trasluce, irónico, esta ofensa) ${ }^{175}$. Si los argentinos la ven como "un empresario de notabilidades" ${ }^{176}$, el polaco la ubica entre los "funcionarios del espíritu"177. En 1960, Borges y Bioy se burlan, no sin curiosidad, de la lista de invitados a una reunión en Villa Ocampo a la que han asistido: “¿Por qué Victoria reunirá esta 
fauna ?", se pregunta Bioy, intrigado por la diversidad política de los asistentes ("Hellen Ferro, un ex peronista; María Rosa [Oliver], comunista declarada; la mujer de Risieri Frondizi ; González Lanuza ; vos y yo, que somos liberales"). No lo convence la hipótesis de Borges (“¿buscará algo en el mundo oficial ?”), y propone : “me parece más probable que haya resuelto ser una gran personalidad, una figura nacional, y crea conveniente asegurarse todos los apoyos", a lo que Borges responde : "Ya lo es".

No puede decirse, en efecto, que no haya logrado serlo y con creces : "Victoria quedaba muy bien rodeada de hombres ilustres. Estos no sólo la admiraban y respetaban : le tenían afecto" ${ }^{178}$, recuerda Bianco. $Y$ es que este aspecto fundamental de su labor editorial coincidía con un entusiasmo que acariciaba desde la infancia : el culto al héroe. Cuando Malraux le quiere hacer un regalo especial, como quien le regala una piedra a Roger Caillois, la invita a un almuerzo con Charles de Gaulle ("el poder corrompe hasta al lucero del alba"179, dirá después Victoria sobre el General francés). "Algo le falta en su colección", le había dicho su amigo, entonces Ministro de Cultura y "número dos" del gobierno de de Gaulle. Ocampo, que nunca coleccionó nada, ni pájaros embalsamados (aunque le gustaban mucho), ni primeras ediciones (aunque tenía varias autografiadas), le pregunta intrigada de qué le estaba hablando. "De su colección de grandes hombres" ${ }^{180}$, le había respondido Malraux con una sonrisa. "Ya le dije que yo no colecciono nada, o mejor dicho, sólo colecciono algo que no se puede colocar en estantes: personas" ${ }^{181}$, repetirá Ocampo después, frente a las insistencias de la mencionada "gentil colaboradora" de Atlántida. Sin dudas, su amigo francés había remarcado el arrojo con el que Ocampo se dedicaba a cultivar relaciones personales con los escritores que admiraba (a T. E., que está muerto, le sigue los pasos hasta hacerse amiga de su hermano y probar, sentada en la cocina de la casa familiar, el pudding casero de su madre ${ }^{182}$ ); probablemente viera en ella algún rasgo fanático. Su padre le hace el mejor chiste al respecto cuando entra por primera vez a la casa de Rufino de Elizalde, despojada y moderna hasta el escándalo de sus vecinos, y le dice, mientras mira el pescado que su hija había puesto arriba de la chimenea : "Deberías pedirle a Keyserling que te donara su esqueleto y podrías ponerlo a la entrada. Quedaría muy bien".

Es cierto que Victoria había soñado con llenar su casa de escritores desde que era chica y que leía a Racine en el jardín de Villa Ocampo. ${ }^{183}$ "De la necesidad de escribir, que tuvo desde niña, derivaba su necesidad de frecuentarlos"184, es la interpretación que hace Bianco. Sin dudas aquel deseo infantil, suerte de novela familiar de excepción en la que ella era exactamente aquella que quería ser, haya impulsado y acompañado la tenacidad de su heroworship. Resulta esencial, sin embargo, cotejar esta pulsión singular de Ocampo (no fue el caso de su hermana Angélica, apenas un año menor, que se crió en la misma casa, leyendo los mismos libros y compartiendo las mismas pasiones y amigos) con la descripción que Elena Croce hace del esnobismo de la élite liberal que cultivaban las mujeres italianas durante las primeras décadas del siglo XX (que es, por otra parte, el mundo que Victoria conoce cuando viaja a Europa en 1908, esa élite intelectual y cosmopolita que otorgaba a sus miembros una pertenencia simbólica tan fuerte que era casi una doble nacionalidad) :

Di fatto, se exteriormente, nel costume, nel corretto anglicismo, l'élite si presentaba come liberale, nell'intimo era romantico-reazionaria, convinta di possedere, per diritto divino, il segreto ineffabile della "personalità" e di doverlo difendere come un Graal. ${ }^{185}$ 
el fantasma infantil y el aprendizaje adolescente, la noción de personalidad se convierte, en efecto, en una forma de religión : "Cierto es que por haber perdido mi fe en otras divinidades había transferido a los grandes escritores mi parte de credulidad" 186 , reconoce Ocampo. Cierta megalomanía que encendían sus sueños de niña y de la que conservará siempre un resabio, encuentra, por otro lado, un lugar en este nuevo credo. El culto a la personalidad de los demás hacía posible, por transitividad, la construcción de la suya propia, devota espectadora pero también par -amiga, colega, conocida o espíritu afín- de aquellas otras; no de otra forma, quizá, imaginaba reunir aquella abstracta e ideal "élite espiritual" (en este sentido, Gombrowicz habla de "emprender el peregrinaje hasta la residencia de San Isidro"187, haciendo de ella una suerte de Virgen de Luján).

a tarea de coleccionar grandes hombres, sin embargo, no le trajo pocos dolores de cabeza, y si bien fue esculpiendo, en parte a través de ellos, su propia estatua para la posteridad, tuvo un alto costo. Entendió rápido que ser una musa implicaba convertirse por momentos, como un personaje mitológico, en una mula (así se define en 1966, una mula entre caballos ; bastarda, subalterna, "menos ágil que el caballo y más que el asno", pero superándolos a ambos "en resistencia y sufrimiento" : "esta, por consiguiente, -dirá al relatar la vida de SUR- es la historia verídica aunque abreviada de una revista y de una editorial, contada por una mula solitaria"188). Mitad musa y mitad mula, mitad hechizo y mitad yugo, Victoria Ocampo se vio muchas veces reducida al rol de una "bonne à tout faire " ("el métier de secretaria y bonne à tout faire de V. O. es como ya les he dicho a menudo una lata", dice en una carta de 1963), algo que había comenzado a sospechar desde el primer año de SUR cuando le escribe a Maetzu: "Imposible ir a Biarritz [...].Tengo la impresión dolorosa de haber pasado un año trabajando para el desierto, en el desierto. No sé lo que les parece la revista a las gentes de quienes más me importa... Estoy deprimida, no se imagina usted lo mucho que he trabajado contra viento y marea." 189

\section{"Ese perfume financiero de la señora Ocampo"}

"La revista duraría poco -aseguraban-. Era un pasatiempo de oligarca, destinado a terminar cuando dejara de ser un juguete nuevo. Todos los lugares comunes que florecen para descorazonar desfilaron" ${ }^{190}$, dice Victoria Ocampo en 1975 en el diario La Opinión. La plata era el lugar común para desacreditarla. Tener suficiente como para costearse una revista literaria sin finalidad de lucro con colaboradores en distintos idiomas, lo que implicaba, además de los gastos editoriales, pagar traductores (y SUR hizo de la valorización del traductor una militancia) pesaba más que cualquier talento o visión en potencia que esta mujer "pasatista" pudiera tener. Pocos imaginaron, cuando apareció, que la revista pudiera ser un proyecto de largo aliento, menos su padre, que la miró y le dijo: "Te vas a fundir. Te conozco"191. La descripción que hace de ella Gombrowicz en 1955 ilustra bien este prejuicio :

[...] dama entrada en años y aristocrática, que nadaba en millones largos y que con tenacidad entusiasta había conseguido hacerse amiga de Paul Valéry, invitar a su casa a Tagore y a Keyserling, tomar el té con Bernard Shaw y hacer buenas migas con Stravinsky. En qué medida influyeron en esas majestuosas familiaridades de la señora Ocampo con sus millones, y en qué medida sus indiscutibles virtudes y talentos personales, es un dilema que no pretendo resolver. El insistente tufillo a millones, ese perfume financiero de la señora Ocampo que producía un cosquilleo un tanto excesivo en la nariz, no me invitaba a conocerla. ${ }^{192}$

Cuadernos LIRICO, 16 | 2017 

austero, el gusto criollo por el understatement y el horror a la ostentación ${ }^{193}$; no había "lujo pobre" que pudiera disimular una fortuna semejante -y menos frente a los escritores-traductores, que fueron los principales destinatarios de ese patrimonio puesto enteramente a disposición de la cultura ("se decía que un escritor francés de renombre había caído ante ella de rodillas gritando que no se levantaría hasta recibir el dinero suficiente para fundar una revue literaria. Obtuvo el dinero porque, -dijo Ocampo-, ¿qué iba a hacer con un hombre arrodillado y que no quería levantarse ? Tuve que dárselo" ${ }^{194}$ ). Basta imaginar lo que era ser invitado a Villa Ocampo. La propiedad que Victoria donó a la UNESCO y que hoy existe aún, donde está la antigua casa rodeada de un jardín, es apenas una parte de lo que era en los tiempos en que intelectuales iban por las tardes a tomar el té o llegaban desde distintas partes del mundo con sus petates a pasar una temporada. La residencia privada que hoy está enfrente de Villa Ocampo entonces no existía, tampoco la calle que las separa; todo era un enorme jardín, con un estanque en el centro donde había patos y gansos, que le permitía al visitante ver por primera vez la casa en perspectiva, sin el portón que hoy la oculta. Atrás de esta, el jardín culminaba en una barranca que llegaba directamente hasta el río.

Era difícil que los europeos no vieran en ella un esbozo, un dejo o al menos un eco de aquel personaje decimonónico que recibió el curioso nombre de "rastacueros". El término, que habría derivado del oficio de aquellos obreros "arrastracueros" que manipulaban las pieles de los animales para su comercio, habría terminado por designar a todo latinoamericano del sur que tuviera fortuna ("prodigalidad y lujo chillón", dirá Darío), dando por sentado que toda riqueza venida de dichos pagos señalaba indefectiblemente al estanciero que la había conseguido vendiendo pieles y cueros ${ }^{195}$. Esta figura, que, en palabras de Víctor Goldgel, "supo quitarles el sueño a las élites", impugnaba al latinoamericano, sobre todo al que venía del Río de la Plata, que viajaba a Europa a pasar temporadas y gastar sus millones :

Por más rico o educado que fuera, ningún latinoamericano podía estar seguro de que en París no lo recibirían con dicho epíteto, revelándose así que, a los ojos de los europeos, su distinción era poco más que una farsa. ${ }^{196}$

De esto mismo se quejaba ya en 1906 Rubén Darío ${ }^{197}$, que en su artículo "La evolución del rastacuerismo" procuró hacer un ajuste de cuentas contra la injusticia que padecían, no sabía explicar por qué capricho, únicamente los hispanoparlantes (¿no eran acaso los yanquis igual de extravagantes y derrochadores con sus tocinos y jamones?, Rubén se indigna). Darío interroga la especificidad del término, y va descartando al exotismo, al derroche y al ridículo como rasgos únicos del rastacuero, dado que cualquier francés podría también presentarlos. Concluye así: "el rastacuerismo tiene como condición indispensable la incultura ; ó, mejor dicho, la carencia de buen gusto." Si bien era cierto que "parvenus ó señorones de aldea, creyeron que Lutecia era conquistable con exceso de colorines y mala ostentación de grandezas"198, no sólo los hispanoparlantes merecían tal epíteto; para él, el rastacuero era un tipo universal sin nacionalidad ni época ni profesión, al que ni siquiera le faltaba en realidad gran fortuna para serlo.

61 Seguramente Darío hubiera defendido el caso de Victoria Ocampo, que se vería a sí misma tal vez como aquella heroína de cuando era niña, Geneviève de Brabant (de quien, según el mito, descenderían las duquesas de Guermantes), que en los grabados del libro que lee aparece "en medio del bosque, vestida con la piel de un animal" 199 como una princesa en état sauvage a quien lo primitivo no le quita lo aristocrático. Pero así como le pasa con el

Cuadernos LIRICO, 16 | 2017 
nombre de este personaje favorito cuando se ve obligada a traducirlo al español -que de Geneviève (heroína aristocrática) pasa a Genoveva (" ¿Te acuerdas de esa mucama tan fea que teníamos? Se llamaba Genoveva"200, le recuerda su tía)- a los ojos de Francia, ella pasa de ser la princesa gala del bosque y la piel, a encarnar el estereotipo del "rastaquouère ". A Ocampo le disgusta el costado parvenu de esas casas lujosas decoradas con mal gusto que visita en Europa y en Estados Unidos, aunque resignifica el término positivamente en su discurso feminista ${ }^{201}$. Más tarde, ya vieja y desencantada, pasa de admirar al escritor a admirar a la mecenas ("A mí me interesaba Ottoline por D. H. Lawrence. Ahora me interesa Ottoline por Ottoline"202). Ya no es más la mujer la parvenue, sino acomplejado el escritor: "Basta de soportarles pavadas a estos genios so pretexto que son genios. Hay que desenmascarar su recóndita tilinguería... o inseguridad frente a la mujer"203. Sin dudas, hubo muchos, como Gombrowicz, que olieron en ella "el tufillo a millones", y la posibilidad, que esa fortuna le daba, de poder tener a un joven escritor francés de rodillas durante horas; otros, sin embargo, como Ansermet, vieron esa plata como la metáfora de una riqueza interior, intelectual y artística, él que cuando la conoce le escribe a Stravinsky en una carta que ha descubierto en su nueva amiga "un Ritz de l'esprit" ${ }^{204}$.

\section{Tropezar con el destino}

BORGES : "La señora de Bullrich abre mañana una carnicería".

BIOY : "Ni el snobismo es sólido". ADOLFO BIOY CASARES, Borges, 1965. Enfin je me heurte à ma destinée sudaméricaine. VICTORIA OCAMPO, Traducción del "Poema conjetural", 1976 "Victoria Ocampo : una mujer desdichada"; así titula Sebreli el capítulo que le dedica en su libro Escritos sobre escritos, ciudades bajo ciudades. El adjetivo se comprende en su sentido más cabal cuando se observan los esfuerzos de la gestión de esta mujer desde la perspectiva del final de su vida (quizá también por eso invirtió en su autobiografía, como T. S. Eliot en su segundo cuarteto, la divisa de la reina María Estuardo) ${ }^{205}$.

En 1966, la revista Primera Plana le dedica una tapa en la que se la ve sentada en el jardín de Villa Ocampo con un abanico bajo unas letras tipografiadas que dicen: “¿Cuánto le debe la cultura argentina ?". El copete precisa : "Ha recibido más odio y amor que nadie en Argentina"206. En 1979, la revista Somos, afín a la dictadura, publica otra tapa : "Murió la Señora Cultura" ("una tapa parece responderle a la otra", comenta perspicaz Ernesto Montequin). Toda una vida entregada a la formación de una élite intelectual (aunque fuera al precio de ser una cultura alta de invernadero ${ }^{207}$ ) que la juventud de los 60 cuestiona con sorna y los nefastos años 70 homenajean, rebajándola. Ocampo queda reducida entonces a ser un triste ideal de maestras de una clase media conservadora que veía en su anti-peronismo su mayor valor. Ya no son revistas provocadoras como Primera Plana ni irreverentes como Atlántida, sino reverenciales, como Somos o Siete días, que publica artículos de la tónica de "Cómo sigue la vida de Victoria Ocampo" y la muestran decrépita, con un tumor que le come la cara.

De las tres fortunas que heredó, sólo le quedó el recuerdo. La religión que profesó por la cultura, ese diletantismo entendido como un placer serio que rechazaba el materialismo 
norteamericano, hizo que nunca aceptase el rédito económico como un fin de SUR y que ni siquiera se permitiese tener inversores del sector privado para compartir los gastos de su mantenimiento. ${ }^{208}$ La manera que tuvo de resolver el desafío de haber querido impulsar la cultura argentina sin sacar jamás un beneficio económico, como buena patricia que era (sacrificada, voluntariosa, ajena al rédito), hizo que pusiera toda su patrimonio a disposición de SUR. En los años 60, su época crítica, se ve obligada a vender la partitura autógrafa de Perséphone que le había dedicado Stravinsky ${ }^{209}$, las primeras ediciones que tenía de Joyce en Christie's, un Boccaccio de siglo XVI y una pequeña tela de Picasso que le había regalado Tota Cuevas. En su correspondencia de 1962 y 1963, cuando viaja a Europa, escribe :

Mi camarote es el más chico en que he viajado desde que nací. ${ }^{210}$

Je n'ai plus vingt ans y tengo que viajar a los 72 como nunca viajaron Tagore a los 64, ni Gabriela ídem (que estaban siempre rodeados de secretarios y amigos).

Quién me diera tener hoy en día (si fuera joven) un riche vieillard que me obsequiara con el consabido mink coat. Pero claro que si fuera joven no aguantaría al vieillard y estaríamos en las mismas. ${ }^{211}$

Roger [Caillois] ha de tener actualmente más renta que yo. ${ }^{212}$

En ese mismo viaje, va a una recepción en lo de Mariano Picón Salas, en ese momento embajador de Venezuela, y anota : "tenía la esperanza de comer gratis." ${ }^{13}$ Ya no le queda ni dinero ni poder para continuar su labor de prócer. El mundo de la cultura, esa casa que ella había querido ordenar, está incluso peor que cuando empezó. La gente "se inclina ante Pelé" 214 pero le pasa caminando a Borges por al lado como si nada; "una cuantas patadas certeras" valen más que una obra genial. Aquella fama, por cuyo roce recibía las burlas de amigos y enemigos, ya no es más una cifra de vanidad, sino de decadencia ("José Bianco es uno de los primeros escritores argentinos y uno de los menos famosos. La explicación es fácil. No cuidó su fama, esa ruidosa cosa que Shakespeare equiparó a una burbuja y que ahora comparten las marcas de cigarrillos y los políticos" ${ }^{215}$, escribe Borges en 1985). Los esnobs, asimismo, ya no son un mal necesario y divertido, suerte de frívolos con un sentido agudo de la calidad e intuitivo buen gusto, sino una multitud que amenaza contra la jerarquía de valores que sus antecesores en los años 20 habían ayudado a desarrollar. Decepcionada del cambalache que dejaron los años 60, Ocampo acusa al pueblo argentino de ser dócil a "una propaganda masiva" que los tiene paseándose "en Torino, en subte o en colectivo" 16 -la cita es conocida- con libros que no pueden entender. "El vulgo" saca a pasear Rayuela como si fuera un accesorio de moda ; ya no leen sino que se decoran con el valor simbólico de autores en boga que, si bien ella ayudó a difundir, no son, en su opinión, los verdaderos referentes de su estándar de calidad literaria. Cuando llama a Cortázar "un escritor para minorías", Ocampo está siendo condescendiente con ese escritor argentino que había sido tan obsecuente con ella ${ }^{217}$; la realidad es que no sólo lamenta que los libros se hayan convertido en mercancías para esnobs que confunden lo bueno con lo mediocre, sino que le apena que tomen por culto lo ridículo, y por sofisticado, de este modo, a un autor mainstream que conquista a su lector queriéndolo hacer sentir inteligente. Ahora es el mercado el que explota "las ramificaciones imprevistas" del viejo esnobismo, y prostituye los valores culturales convirtiéndolos en bienes de consumo : el esnobismo es ahora un factor, dice Ocampo, no debe "echarse en saco roto". Esta metáfora de 1966 parece continuar aquella de 1927 : se ha pasado del canasto de fin de semana al saco roto de la cultura alta.

67 Su cruzada por el calidad, esa obsesión que nunca la abandonó, había fracasado. "La calidad" era, en ese mundo nuevo, "impopular"; Ocampo le pone bastardillas y agrega : 
"con eso queda dicho todo" 218 . El mensaje es claro: el éxito masivo de un producto asegura su baja calidad (recordemos que para el joven Borges que un libro se vendiera bien era signo de que era malo, y que Arturo Cancela siempre decía que había vendido menos libros de los que había vendido, por vanidad). Se indigna así frente a este caos en las jerarquías como la "bonne à tout faire" que mira desolada el desorden que le han dejado en la casa que era su tarea limpiar. Debería evacuar a Pelé y a Goyeneche de la terraza, bajar también esa trompeta de Duke Ellington (que personalmente adora), y hacerlo subir con cuidado a Borges, que está sentado en un patio interno, y después a Caillois (lo que seguramente hubiera irritado al primero, tener que compartir terraza con alguien con quien le costaba compartir hasta un cafée ${ }^{19}$ ).

Nadie iría a leer SUR en las décadas que siguieron a su muerte (tampoco la leían ya en sus últimos años). En las páginas de esa revista, no obstante, quedan las pruebas de aquel estándar que nunca pudo explicar, pero del que dejó casi trescientos cincuenta tomos de ejemplos. Bianco se sorprende, ya grande y con la perspectiva del tiempo, al releerla de a poco todas las noches; era mejor de lo que recordaba. A Bioy le pasa lo mismo; en sus memorias llega al fin el elogio que le negó a su cuñada durante toda su vida. Permanece hasta el día de hoy, en cambio, esa excepcionalidad que Ocampo había construido como se esculpe un busto. Todos aquellos testimonios sobre ella citados al comienzo de este trabajo, que recurren reiteradamente al adjetivo "innato" para preceder las virtudes que le reconocen, son quizá un síntoma detrás del cual se esconde esa construcción pulcra y tenaz que hizo de sí misma, ese camino de mulita para el cual no existían baqueanos capaces de descifrarlo (porque la mula, claro está, la encuentra en el Facundo).

Victoria Ocampo fue elitista, cosmopolita, y tan francófona como francófila ${ }^{220}$. Analizar qué lugar ocupó el esnobismo en estas categorías será el objetivo de futuros trabajos. Su bisabuelo paterno había sido concuñado y muy compinche de Vicente Lucio López y amigo y administrador de los bienes personales de Sarmiento -su hija (tocaya y madrina de Victoria) una amiga que este último admiraba y quería. A su tía abuela paterna [Adela Ocampo de Heimendahl], por otra parte, la había pintado Renoir. En su árbol genealógico podía reunir a una indígena originaria del Paraguay, a un conquistador español, al escritor argentino José Hernández y al pintor argentino Pridiliano Pueyrredón. Había tomado clases a los dieciséis años con Marguerite Moreno, viuda de Marcel Schowb y una leyenda en la historia de la declamación que había organizado el entierro del mismísimo Stéphane Mallarmé. A los dieciocho, asistió a los cursos de filosofía que Bergson impartía en el Collège de France y tuvo por festejante a Maurice Rostand, hijo del poeta que admiraba. Había, es cierto, muchos elementos en su vida que le permitían imaginar y creer en su excepción, pero que sobre todo le permitían construirla. Más que el paradigma de una esnob, Victoria Ocampo supo llevar, durante años, el fuego sagrado del buen gusto que perseguían los esnobs sin nunca haber compartido con ellos el mismo esnobismo. Ella, que había sabido ser la reina de los esnobs, la soberana de los middlebrows, su más certera y justa guía espiritual, se queda sola y empobrecida en una casa que ya no le pertenece (la dona a la UNESCO en vida). Borges titula el homenaje que le escribe en 1962 "Un destino". Explica por qué :

Busco un término de comparación. Banchs es un gran poeta o (lo que sin duda es más) un poeta, pero si un demonio capaz de cambiar el pasado hiciera que sus versos no hubieran sido, el mundo sería menos bello pero la trama de la historia no habría sido alterada. Inversamente, el proceso de nuestra cultura no es concebible sin la gravitación y el estímulo de Victoria Ocampo. ${ }^{221}$ 
Ella fue la esnob que sembró el desierto argentino y terminó, como su ídolo T. E. Lawrence, hablando sola en el desierto. En el último tomo de sus Testimonios, el décimo, lo dice. Ya ha entendido, y ha aceptado al fin, cuál era la forma que impensadamente, burlando sus planes, había tomado su destino : "La esperanza secreta de que me oigan hoy más que ayer es disparatada. [...] Pero eso de predicar en el desierto es una vocación como cualquier otra." 222

\section{NOTES}

1. En 1927, se publica en La Nación el artículo “Arte y moda" del musicólogo Ernesto de la Guardia. Entre 1926 y 1927, la revista Claridad publica varios artículos comentando las representaciones musicales de Ernest Ansermet con la participación de Victoria Ocampo como promotora de la Asociación del Profesorado Orquestal (APO) y, en particular, como recitante en Le Roi David de Honneger, estrenada el 29 de agosto de 1925. Sobre la recepción de este espectáculo, ver Omar Corrado, "Victoria Ocampo y la música: una experiencia social y estética de la modernidad”, Revista Musical Chilena, Año LXI, JulioDiciembre, 2007, № 208, pp. 37-6B; del mismo autor, “'Vanguardistas' en el Colón: la gestión de Victoria Ocampo, Alberto Prebisch y Juan José Castro (1933)”, Música e Investigación, Ns. 14-15, 2004, pp. 15-26.

2. Victoria Ocampo, Índice de SUR 1931-1966, no 303-304-305, diciembre 1966, p. 17. De hecho, "el nombre de Sudamericana nació de la imposibilidad de seguir llamándole Sur a la Editorial porque esta palabra tenía un dejo revolucionario e iconoclasta... Los libros de Mounier y Maritain publicados por Sur no recibieron el imprimatur de la Nueva Editorial". Las itálicas son nuestras.

3. José Bianco, Ficción y reflexión. Una antología de sus textos. México: Fondo de Cultura Económica, 1988, p. 404. Sebreli evoca este episodio de 1937 (cuando la revista católica nacionalista Criterio acusa a SUR de "izquierdista") como un momento clave en que, a partir de las colaboraciones de Jacques Maritain, católico democrático, Emmanuel Mounier, personalista cristiano del grupo de la revista Esprit, y los existencialistas cristianos Nicolás Berdiaev y León Chestov, SUR define su posición antifascista y antinazi. Ver "Una mujer desdichada: Victoria Ocampo", Escritos sobre escritos, ciudades bajo ciudades 1950-1997. Buenos Aires: Sudamericana, 2015.

4. Jorge Luis Borges, "Un destino", Testimonios sobre Victoria Ocampo. Buenos Aires: La flor, 1962 , p. 50.

5. En la correspondencia con Ocampo, Caillois le cuenta el siguiente cuento (y llega tarde, Victoria ya lo había escuchado): "Sais-tu que Mauriac a reçu trois jours après la mort de Gide le télégramme suivant : 'L'Enfer n'existe pas. Tu peux te dissiper. Préviens Claudel. Signé : Gide", Odile Felgine (ed.), Roger Caillois et Victoria Ocampo. Correspondance : 1939-1978. Paris: Stock, 1997, p. 318. La carta está fechada el 7 de abril de 1951.

6. "Gide vivant", Les Temps Modernes, $\mathrm{n}^{\circ}$ 66, mars 1951, repris dans Situations IV, Gallimard, 1964. 
7. Enrique Anderson Imbert, "El liberalismo de Victoria Ocampo”, Testimonios sobre Victoria Ocampo, op. cit., p. 21. Las itálicas son nuestras. Treinta y seis años después, dirá de Ocampo María Teresa Gramuglio: "se convierte en una protagonista conspicua del campo intelectual, es mecenas, operadora cultural, escritora, académica, funda una revista que es casi una institución, y con todo siempre es considerada con cierta condescendencia, siempre se le encuentra algo del autodidacta y del dilletante, como si estuviera 'fuera de lugar”", María Teresa Gramuglio, “Victoria Ocampo y los conflictos de la cultura argentina", Prismas. Revista de historia intelectual 2, Universidad Nacional de Quilmes, 1998, p. 233.

8. Adelaida Gigli, “Victoria Ocampo: V. O.”, Contorno, nº 3, septiembre 1954 en Contorno: edición facsimilar. Buenos Aires: Biblioteca Nacional, 2007, pp. 25-26.

9. Sin firma, “A los 70 y pico... una niña terrible”, Atlántida, no 1212, marzo 1968, pp. 38-41.

10. Victoria Ocampo, “Aclaraciones”, SUR, n 314, septiembre-octubre 1968, p. 143.

11. Ocampo tematiza la historia de Agueda, su antepasada indígena, desde una perspectiva feminista en varios momentos de su obra, entre los cuales puede resaltarse “Mujeres en la Academia”, Testimonios, Décima Serie (1975-1977). Buenos Aires: Sur, 1978, p.

22. Cuando menciona la ascendencia guaraní de manera aislada, sin evocar el nombre y la historia de Agueda, el dato genealógico toma un ribete, entonces sí, más esnob (en el sentido de que implica un "entre nos" específico, a saber, aquellos que pueden descifrar la alusión como el signo de una pertenencia de clase): "Leo complacida (soy del Cuzco por mi ascendencia paterna) que en el Imperio Inca la mujer representaba una fuerza de trabajo y garantía de producción de la especie debidamente apreciada", "El último año de Pachacutec", ibid., p. 45.

12. En 1930, el diario La Nación menciona su llegada a los Estados Unidos y transcribe la declaración citada. Este recorte se encuentra en Victoria Ocampo, Álbum de viaje, Buenos Aires - París - Berlín - Nueva York, 1929-1931, edición limitada al cuidado de Nicolás Helft y Ernesto Montequin. Buenos Aires: Asociación Amigos Villa Ocampo y Villa Ocampo, 2013. 13. Pablo Gianera, La música en el grupo Sur. Una modernidad inconclusa. Buenos Aires: Eterna Cadencia, 2011, pos. 1470. Sobre las relaciones de Ocampo con la música, ver Omar Corrado, Victoria Ocampo y la música: una experiencia social y estética de la modernidad, Revista Musical Chilena, Año LXI, Julio-Diciembre, 2007, Nº 208, pp. 37-6B.

14. Conversaciones con Ernesto Montequin, a quien le debo esta y muchas otras informaciones que fueron fundamentales para este artículo; le debo también reflexiones, lo que podría llamarse una verdadera educación en temas ocampianos. Victoria cuenta este episodio con "el capitán Z." en Autobiografía III. La rama de Salzburgo. Buenos Aires: Sur, 1982, pp. 86-94.

15. En 1946, época de racionamiento y precariedad en Londres, Ocampo va a almorzar a casa de un amigo de T. E. Lawrence. No conoce a los demás comensales; uno de ellos, da muestras de una atención de lo más sencilla y se ocupa de servirle cada vez para que ella no tuviera que levantarse. Cuando se va, Ocampo pregunta quién era y se entera momento en que casi se desmaya de esnobismo- de que aquel señor gentil era el hermano de la reina Isabel: "Esta es la gran Inglaterra, la Inglaterra que admiro -pensé. Y confieso que estuve al borde de una crisis de snobismo social. Pero se me pasó", "El snobismo", Testimonios, octava serie 1968-1970. Buenos Aires: Sur, 1971, p. 275. En este artículo, Ocampo se explaya sobre el esnobismo social, sus variables, léxico y ritos según la clase que se enarbole.

16. Corrado Fatta, Du snobisme. Un chapitre d'Antropologie. Paris: Buschet Chastel, 1961, p. 11. 
17. Frédéric Rouvillois, Histoire du Snobisme. París: Flammarion, 2008, p. 31.

18. Ibid.

19. "C'est un état d'âme [...] indéfinissable, pour lequel il a fallu créer un nouveau mot : les Snobs sont les Snobs, voilà !”, ibid.

20. Víctor Goldgel, "Entre dandis y rastacueros. Aproximaciones al esnobismo del siglo XIX latinoamericano", Revista digital, año 3, número 5, 2004.

21. Joseph Epstein, Snobbery: the American versión. Boston: Houghton Mifflin, 2002, p. 91. Las cursivas son nuestras.

22. Ibid., p. 13.

23. Para La Rochefoucauld, la imitación siempre tenía algo de falso y de incierto, dice Fatta, razón por la cual "le snob a la conscience plus ou moins obscure d'une sorte d'infériorité, d'un défault ou d'un manque ; la conscience qu'il ne saurait subsister par luimême comme personne", Corrado Fatta, op. cit., p. 236.

24. Víctor Goldgel, op. cit., p. 239.

25. Ibid., p. 241.

26. Corrado Fatta, op. cit., p. 85.

27. Frédéric Rouvillois, Histoire du Snobisme. París: Flammarion, 2008,

28. Philippe Jullian, Dictionnaire du snobisme. Paris: Librairie Plon, 1958.

29. Victoria Ocampo, "El snobismo", Testimonios, Octava serie (1968-1970). Buenos Aires: Sur, 1971, p. 276.

30. Corrado Fatta, Du snobisme, un chapitre d'antrolopolgie. Paris: Buchet-Chastel, 1961.

31. Émilien Carassus, Le Snobisme et les lettres françaises de Paul Bourget à Marcel Proust: 1884-1914. Paris: Librairie A. Colin, 1966.

32. Sean Latham, " Am I a snob?": Modernism and the Novel. Cornell University Press, 2003.

33. Joseph Epstein, op. cit.

34. Jacques Boulenger, Monsieur ou le Professeur de snobisme. Paris: le Divan, 1923.

35. Marcel Boulenger, Éloge du snobisme. Paris: Hacette, 1926.

36. Jacques Boulenger, Sous Louis-Philippe. Les Dandys, con prefacio de Marcel Boulenger. Paris : P. Ollendorff, 1907.

37. Jacques de Ricaumont, Éloge du snobisme. Paris: Mercure de France, 1993.

38. Aldous Huxley, "Selected Snobberies", Music at night, p. 177.

39. Un poeta como Carlos Mastronardi, por ejemplo, podía convertirse en un objeto esnob: "BORGES: 'Un autor como Mastronardi o Mallarmé da a sus admiradores la satisfacción vanidosa de pertenecer a los happy few'. BIOY: 'Como Toulet a nosotros'. BORGES: “Como Toulet a nosotros”', Adolfo Bioy Casares, Borges. Buenos Aires: Destino, 2006, p. 1202.

40. Raphaël Enthoven y Adèle Van Reeth, Le Snobisme. Questions de caractère. París: Plon, 2015 , p. 5. El lector encontrará la introducción a este diálogo entre Van Reeth y Enthoven sobre el esnobismo en la sección “Traducciones” de este número.

41. Ibid., p. 15.

42. Ibid., p. 47.

43. Witold Gombrowicz, Diario. Barcelona: Seix Barral, 2005, p. 81.

44. Arthur Koestler, "An Essay on Snobbery”, The Trail of The dinosaur \& Other Essays.

Londres: Collins, 1955, p. 86.

45. Witold Gombrowicz, op. cit., p. 79.

46. Ibid., pp. 78-79.

47. Frédéric Rouvillois, op. cit., p. 23.

48. Sean Latham, op. cit., p. 14. 
49. “Victoria Ocampo es un 'dandy'. Después de Mansilla, es el más grande de los 'dandies' de la literatura argentina. Y las capas y las boinas del General tienen sus dignas continuadoras en las preferencias arrogantes de la autora de 'La laguna de los nenúfares"', Marcos Victoria, Un coloquio sobre Victoria Ocampo. Buenos Aires: 1934, p. 26. 50. Ibid., p. 207.

51. Cuando pasa esa primera etapa de encuentro y fascinación con España, Ocampo dona este y otros dos retratos que le hace Miguel Nieto al Museo de Bellas Artes. Se deshace así de esas imágenes que hacen de ella un arquetipo estético de la criolla colonial y no coincidían con su proyecto de encarnar la imagen de la mujer moderna. Este manejo cuidado de su imagen la acompañó hasta el final. "BORGES: 'En El Mundo publicaron una fotografía de Victoria. Esta se enojó mucho, les escribió una carta y les mandó fotografías autorizadas." Adolfo Bioy Casares, op. cit., p. 702. Plus Ultra, a.VIII, n.83, marzo 1923.

52. Sin autor, Parisina. Espejo de las elegancias parisienses, $n^{\circ}$ 20, año III, 1 de abril, p. 19.

53. Carlos Morla Lynch, En España con Federico García Lorca, páginas de un diario íntimo 1928-1936. Madrid: Aguilar, 1958, p. 115

54. José Bianco, op. cit., p. 232.

55. Juan José Sebreli, Escritos sobre escritos, ciudades bajo ciudades 1950-1997, op. cit., p.

56. Adolfo Bioy Casares, op. cit., p. 199.

57. Waldo Frank, South American Journey. Nueva York: Duel, Sloan and Pearce, p. 103.

58. Sin firma, “A los 70 y pico... una niña terrible”, op. cit., p. 39.

59. Ibid., p. 235.

60. Ibid., p. 115.

61. Ibid., p. 236. César Magrini cuenta la primera vez que la vio en una playa de Mar del Plata: “Alguien dijo a mi lado: 'Ahí va Victoria Ocampo'. Fue como si me hubiesen avisado del descenso del Espíritu Santo. ¡Victoria Ocampo, la de los libros!”, Testimonios sobre Victoria Ocampo, op. cit., p. 195.

62. Adolfo Bioy Casares, op. cit., p. 36.

63. Ibid., p. 722.

64. Witold Gombrowicz, "Aurora , revue de la Résistance”, traducida por A. Gerschenfeld, Varia II. Paris: Christian Bourgois Éditeur, 1989, p. 170.

65. Nótese que en un principio, entre 1952 y 1955, gracias a Murena, es bien recibido. Cfr. Sebreli "Revisitando SUR", El tiempo de una vida: Autobiografía. Buenos Aires:

Sudamericana, 2005; Escritos sobre escritos, ciudades bajo ciudades 1950-1997, op. cit. John King, Sur. Estudio de la revista argentina y de su papel en el desarrollo de una cultura 1930-1970. México: Fondo de Cultura económica, 1989.

66. Juan José Sebreli, El tiempo de una vida: Autobiografía., op. cit.., p. 181.

67. Juan José Sebreli, “Borges: el nihilismo débil”, Escritos sobre escritos, ciudades bajo ciudades 1950-1997, op. cit., p.

68. Ibid.

69. Ibid.

70. Se conocen en 1929. Rivas Mercado financia su campaña presidencial, en la cual lo acompaña, elección que los porfiristas les robarán después con fraude y persecución.

71. Elena Croce, Lo snobismo liberale. Milán: Adelphi Edizioni, p. 10.

72. Juan Álvarez Márquez, Más allá del ruego: vida de Susana Soca. Montevideo: Linardi y Risso, 2007, p. 143-144.

73. Anne Ansermet, Ernest Ansermet, mon père. Lausanne: Payot, p. 69. Las itálicas son nuestras.

74. Juan José Sebreli, Cuadernos. Buenos Aires: Sudamericana, 2010, p. 84. 
75. Ibid., p. 85

76. Ibid. El título alude probablemente a Les Champs magnétiques, libro fundador del surrealismo que publican André Bretón y Philippe Soupault en 1919. El primer número se inicia con un texto de Elvira de Alvear titulado "Amigo lector" en el que presenta a su revista como "un campo magnético" que atraerá norte y sur, escritores y tendencias, preocupada por dejar una "documentación de su época" que evitará "el color local” pero preservará "un acento argentino". Imán, concluye, "es por y para fronteras ilimitadas"; promete ser "panamundiales" y se proclama "un imanato". Aparecen las firmas de LeónPaul Fargue, Jean Giono, Emilio Lascano Tegui, Xul Solar, Bruno Barilli, Vicente Huidobro, Henri Michaux, Jaime Torres Bodet, Robert Desnos, Franz Kafka (traducido por Arqueles Vela), Miguel Ángel Asturias, Eugène Jolas (traducido por Manuel Altolaguirre), Benjamín Fondane, Xixto Martelli, Alejo Carpentier (con un fragmento de Ecué Yamba-O), Hans Arp, Boris Pilniak (traducido por Miguel Ángel Asturias), John Dos-Passos (traducido por Carlos Enríquez) y Arturo Uslar Pietri. Es de particular interés la encuesta publicada "Conocimiento de América Latina", a la que responden diez personalidades del surrealismo parisino: Ribemont Dessaignes, Robert Desnos, Georges Bataille, Michel Leiris, el citado Philippe Soupault, Walter Mehring, Alfred Kreymborg, Zdenko Reich, Roger Vitrac y Nino Frank.

77. Estela Canto, Borges a contraluz. Madrid: Espasa Calpe, Colección Austral, 1989, pp. 189-190.

78. Adolfo Bioy Casares, op. cit., p. 628.

79. Juan José Sebreli, op. cit., p. 86.

80. Ocampo se enoja con él cuando se entera de que no comparte su misma opinión respecto de la obra de Cocteau, "La Voix Humaine", a cuyo primero ensayo general había ido Victoria con Ramón Gómez de la Serna y Delia del Carril. No puede perdonarle la falta de rigor en el juicio estético (dice que se deja engañar por el "côté sentimental de la pièce", que a su vez califica de "prostitution du Coeur"). Cartas a Angélica y otros. Buenos Aires: Sudamericana, 2001, p. 29.

81. Ocampo le cuenta estos encuentros a su hermana Angélica por carta. Ver ibid.

82. Juan José Sebreli, op. cit., p. 86.

83. Ibid., p. 87.

84. Ibid., p. 89.

85. Ibid.

86. Ibid., p. 92

87. Victoria le cuenta enojada en una carta a Angélica que Tota comió con Jean-Michel Frank y cuando este le preguntó quién era en Buenos Aires el equivalente de los Noailles, o quién era el referente del buen gusto de la capital argentina, Tota le había respondido "personne". A Ocampo la actitud de su amiga la condesa de Cuevas le parece de una ingratitud sin nombre. "Podría haber mencionado a los Born", le dice a su hermana, quienes le habían encargado en esos años, por otra parte, un trabajo a Frank.

Agradecemos estas informaciones a Ernesto Montequin, para quien la mención a los Born escondería una ofensa mayor: que su amiga tampoco la hubiera nombrado a ella.

88. En 1962, le pide al hermano menor de María Rosa Oliver, Samuel (que sería director del Museo de Bellas Artes entre 1963 y 1976) que la ayude a ponerle un passse-partout a la tapicería de Léger y a colgar el Picasso: “También me gustaría colgar el Picasso (la alfombrita)", ibid., pp. 122-123.

89. Victoria Ocampo, Autobiografía I. El archipiélago, op. cit., p. 14. 
90. Victoria Ocampo, "Jacques Rivière, à la trace de Dieu”, Testimonios primera serie, op. cit., pp. 77-78.

91. En el libro The Stylemakers hay una foto de un recorte de una nota "especial para [la revista] El hogar" que Marie Pascal le hace a Jean-Michel Frank en París, justo antes de su viaje a Buenos Aires (es Ignacio Pirovano quien lo invita), y dice: "Gran artista decorador, es huésped de Buenos Aires".

92. Conversaciones con Ernesto Montequin.

93. Boldini llega a manifestar el deseo de pintar a Ocampo, pero su marido Mónaco Estrada se lo impide.

94. En Picasso à Biarritz, été 1918 se pueden ver los croquis que Picasso hace de Madame Errazuriz y de su villa, a la que el libro le dedica un capítulo, "La Mimoseraie”, pp. 65-74. Jean François Larralde y Jean Casenave, Picasso à Biarritz, été 1918. Paris: Editions Lavielle, 1995. "Venus de tous horizons, aristocrates, marchands et peintres, écrivains et poètes, musiciens et personnalités mondaines sont reçus dans le salón de La Mimoseraie, confirmant ainsi le rayonnement personnel d'Eugenia Errázuriz et l'étendue de ses relations", Alejandro Canseco-Jerez, La mecène de Picasso. Paris: Artextos, 208, p. 123. 95. La mención se encuentra en el séptimo tomo, Le Temps retrouvé. Proust convierte a Eugenia en un modelo particular de mujer, que describe diciendo "l'art les avaient touchées comme la grâce. Et comme au XVIIe siècle d'illustres dames entraient en religion, elles vivaient dans un appartement rempli de peintures cubistes, un peintre cubiste ne travaillant que pour elles et elles ne vivant que pour lui".

96. Pierre-Emmanuel Martin-Vivier (dir.), Jean-Michel Frank : un décorateur dans le Paris des années 30, exposition, Paris, Fondation Pierre Bergé-Yves Saint-Laurent, 2 octobre 2009-3 janvier 2010. Paris: Norma éd., 2009, p. 18.

97. Ocampo cuenta esta escena en "La aventura del mueble", primer artículo que publica en SUR: "Cuando Jean Cocteau visitó por primera vez el departamento de [Jean-Michel] Frank -joven decorador francés - departamento en cuyo vestíbulo no había nada, ni una silla, ni una mesa, dijo al salir: 'L'appartement est charmant! Quelle dommage qu'il ait été cambriolé!' Pues bien, yo no lo lamento y estoy contenta de haber nacido en la época del 'cambriolage' de las casas", SUR, no 1, verano de 1931, p. 171.

98. Alejandro Canseco-Jerez, op. cit., p.3.

99. Catálogo Amigos del Arte, 1924-1942. Buenos Aires: Malba, 2008.

100. Oscar Terán ubica esta revista en la línea de los "modernos intensos"; menciona sus raíces anarquistas, habla de "la fuerte y explícita influencia soreliana [...] que bien podía colocarlos cerca de posiciones fascistas o bolcheviques, y que compartían con ellas su carácter antiburgués, antiliberal y extremista", Historia de las ideas en la Argentina: Diez lecciones iniciales (1810-1980). Buenos Aires: Siglo XXI, 2008, p. 210.

101. Inicial, año I, no 7, diciembre 1924, p. 560.

102. Rubén Darío, “A propósito de Mme. de Noailles”, Opiniones. Madrid: Librería de Fernando Fé, 1906, p. 95.

103. Ibid.

104. Victoria Ocampo, "Correspondencias", Testimonios, Primera serie. Madrid: Revista de Occidente, 1935, p. 100.

105. Testimonios sobre Victoria Ocampo. Buenos Aires: La flor, 1962. Este volumen es una sorpresa que preparan sus colegas y amigos; si bien aspiraban a reivindicar y defender su labor de las provocaciones y las indiferencias de los años 60, no lograron sino hacerla sentir aún más humillada una vez que, por error pero ya demasiado tarde como para detenerlos, descubre lo que están tramando. Que personajes de la cultura universal como 
Denis de Rougemont, Lanza de Vasto, T. S. Eliot, Vittorio De Sica, Le Corbusier, Leonard Woolf y tantos más (los Miembros de la Comisión llegan a doscientos veintiséis) tuviesen que escribir afirmaciones del tipo "I am glad to place myself on record as one of those who recognized her international services to literature", como escribe Eliot, en lugar de elevarla, a sus ojos, la rebajan.

106. José Luis Romero, ibid., p. 311.

107. Claridad, Buenos Aires, $\mathrm{n}^{\circ}$ 138, 10 de julio 1927, snp. Las itálicas son nuestras. La reacción de Barletta se funda seguramente en el hecho de que, como lo explica Omar Corrado en los artículos citados, "la aristocracia porteña había descubierto en la modernidad musical una nueva marca de distinción." En la correspondencia de Ocampo con Arturo Jauretche, por ejemplo, el escritor peronista le reprocha el haberle enviado un disco cuando sabe muy bien que la gente como él no tiene formación musical.

Norberto Galasso (ed.), Dos argentinas Arturo Jauretche, Victoria Ocampo : correspodencia inédita : sus vidas, sus ideas. Rosario: Homo Sapiens, 2015.

108. Parisina, $\mathrm{n}^{\circ} 18$, año III, 20 de enero, p. 4.

109. Parisina, $\mathrm{n}^{\mathrm{o}}$ 19, año III, 20 de febrero, p. 26

110. Ver nota 42.

111. Parisina, $\mathrm{n}^{\circ}$ 18, año III, 20 de enero, p. 1 . Sobre dilentatismo y escepticismo, ver Richard Hibbit, Dilettantism and its values. From Weimar Classicism to the fin de siècle, Legenda, 2006.

112. "Prólogo de Ernesto Sábato" en Laura Ayerza de Castilho y Odile Felgine, Victoria Ocampo. Barcelona: Circe, 1993, pp. 11-12.

113. Victoria Ocampo, "Aclaraciones", $i$ bid.

114. Adelaida Gigli, op. cit., p. 2.

115. Jospeh Epstein, op. cit., p.

116. No incluye, por ejemplo, a Paul Valéry en la Consejo Extranjero de SUR, aunque hubiera podido hacerlo sin problemas, simplemente porque no era parte de la misma. No usa nombres que no pueda justificar, lo que no significa no use aquellos que sí considera legítimo evocar.

117. Witold Gombrowicz, Diario, op. cit., p. 477.

118. Arthur Koestler, op. cit., p. 82.

119. Adelaida Gigli, op. cit., p. 1. Las itálicas son del texto.

120. "Se sentía hija de Sarmiento, a quien recordaba fielmente", escribe Borges en "V. O.", Textos recobrados (1956-1986). Buenos Aires: Emecé, 2003. En efecto, Ocampo despliega en su obra una verdadera "operación Sarmiento". Cfr. Autobiografía (primer y segundo tomo), "Sarmiento" en Testimonios segunda serie (1941), "Aries y capricornio" en Testimonios séptima serie (1967), Índice general de la Revista Sur 1931-1966, op. cit., los números 47 (1938) y 341 (1977) de SUR; el número 46, por otro lado, consagrado a la importancia de las élites culturales en la crisis mundial, titulado "Defensa de la inteligencia", comienza con el artículo "Con Sarmiento".

121. Omar Corrado observa este modus operandi en su relación con la música: "Frente a lo que la música suscita en ella, su método interpretativo consiste en la exploración incesante de las analogías con el paisaje, con la pintura, y en asociaciones con recuerdos de su infancia, con personas conocidas, en un intento por encontrar una sintaxis entre los sonidos y la 'prosa del mundo' capaz de traducir y comunicar su experiencia." Omar Corrado, op. cit.,

122. “Así como Juana oía voces, yo veo cada vez más claro lo que será o podría ser la revista", le escribe a Ortega en Índice de SUR 1931-1966, op. cit., p. 7. 
123. "Cholulo, la: m. y f. Admirador incondicional de los integrantes más famosos de la farándula. 2. Por ext. Persona que por frivolidad busca relacionarse con personajes famosos de la política, vida social, arte, etc. O que habla repetidamente de ellos. Adj. Frívolo, superficial. (El término proviene del nombre de la protagonista de la tira cómica 'Cholula, loca por los astros', creada por Horacio Meyrialle (con dibujos de Toño Gallo) publicada en la desaparecida revista Rico Tipo)" en Oscar Conde, Diccionario etimológico del lunfardo. Buenos Aires: Libros Perfil, 1998.

124. Álbum de viaje, Buenos Aires - París - Berlín - Nueva York, 1929-1931, op. cit., snp.

125. Victoria Ocampo, Cartas a Angélica, op. cit.,p. 82. La carta es del 15 de diciembre de 1948.

126. "Viernes, 27 de abril. Con Pezzoni y Silvina, vamos a almorzar a San Isidro, donde se agasaja a Vivien Leigh. A los postres Victoria me exige perentoriamente que la fotografíe con la actriz. Borges comentará después: 'Cada día está más modesta y más ambiciosa. Ambiciosa de small mercies que no van hacia ella." Adolfo Bioy Casares, Borges, op. cit., p. 764. La entrada es de 1962. Sobre la visita de Helen Hayes narrada por Borges, que también asiste a Villa Ocampo en esa ocasión, ver p. 751.

127. Ibid., p. 77. La carta está fecha el 6 de diciembre de 1946.

128. Ibid., p. 93. La carta está fechada el 7 de diciembre de 1951.

129. Ibid., p. 126. La carta está fechada en 1962.

130. Sobre el culto de Ocampo a T. E. Lawrence (apropiación que disputa con Borges, por otra parte; él cederá), ver la reseña Ezequiel Martínez Estrada sobre el libro que ella escribe sobre el piloto y escritor inglés en "Victoria Ocampo : 338171 T. E.", SUR , no 100, enero 1943, pp. 100-107. Gonzalo Aguilar estudia con agudeza esta relación en "La admiración inconmensurable: Victoria Ocampo y T. E. Lawrence”, Episodios cosmopolitas en la cultura argentina. Buenos Aires: Santiago Arcos editor, 2009. Esta expectativa religiosa del escritor, tal como la articula en una carta dirigida a Caillois en 1939, inunda y atraviesa su obra: “En tout cas, pour moi, je n'ai pas d'hésitation : un intellectuel doit être un 'saint', je voudrais même qu'il soit visiblement consacré : par des voeux, un vêtement, n'importe quoi qui le retranche du siècle. Alors seulement, il peut avoir de l'influence (et a le droit d'en avoir)." Odile Felgine (ed.), Roger Caillois et Victoria Ocampo. Correspondance : 1939-1978., op. cit., p. 27.

131. "Vers la même époque, de passage à Paris, celle-ci demanda à des amis d'organiser pour elle une rencontre avec Lacan. Devant leur étonnement à l'idée saugrenue qu'elle pût s'intéresser à ce grand maître de la pensé freudienne, elle prononça ces mots superbes : 'Era el amantito de la mujer de Drieu'.” Elisabeth Roudinesco, Jacques Lacan, Esquisse d'une vie, histoire d'un système de pensé, Fayard, 1993, p. 114.

132. Todas las dedicatorias se encuentran en el catálogo bilingüe de la exposición que se hizo en la Casa de América Latina, en París, en 2014, Victoria Ocampo y Francia. Literatura y otras pasiones, editado por Ernesto Montequin.

133. Arthur Koestler, op. cit., p. 70.

134. Lena Dunham y Jennie Konner, Girls, “Goodbye Tour”, season 6, episode 9, salió al aire el 9 de abril de 2017.

135. Cartas a Angélica, op. cit., p. 171. La carta está fechada el 5 de diciembre de 1963.

136. Victoria Ocampo, Un viajero y una de sus sombras. Keyserling en mis memorias. Buenos Aires: Sudamericana, 1951.

137. "Nunca fumé en boquilla, ni amenacé a nadie con esa arma tan manifiestamente inofensiva. De usar proyectiles, los uso de mayor calibre. Una vez le tiré una plancha a alguien. Reservo el nombre para mis memorias; pero adelanto que no se trataba de 
ningún empleado mío, sino de un aristócrata." SUR , nº 314, septiembre-octubre 1968, p. 143.

138. Victoria Ocampo, Cartas a Angélica, op. cit., p. 24.

139. Ibid.

140. Ibid., p.. 17.

141. Ibid p. 21

142. Ibid.

143. Ibid., p 27.

144. Jean Hugo, Le Regard de la mémoire. Arles: Actes Sud, 1989.

145. Ibid., p. 34.

146. Ibid., p. 29.

147. Ibid., p. 34.

148. En la correspondencia con Ansermet, comentan dicho artículo y hablan del libro de Debussy que el supuesto "señor X" le recomienda leer a Ocampo, y del que incluso le envía un ejemplar (no existían en ese momento ediciones en Buenos Aires). Queda claro que ella es el señor X. Vies croisées de Victoria Ocampo et Ernest Ansermet : Correspondance, 1924-1969, édition de Jean-Jacques Langendorf. Paris: Buchet-Chastel, 2005, pp. 185-199. 149. Victoria Ocampo asiste en 1913 al estreno de Le Sacre du printemps, famoso por el escándalo que produjo en el público (llega a ir la policía al Teatro de Champs Elysées). La escritora se referirá a esta experiencia reiteradas veces, ya sea en artículos, discursos o entrevistas. La escena del estreno cristaliza su despertar a la modernidad; la música de Stravinsky la deja en un estado de conmoción (siente que la ha revolcado una ola). Muchos silban, sisean, insultan; otros aplauden. Ocampo no sabe qué hacer, tiene sensaciones encontradas y no conoce los códigos que separaran a los esnobs del resto, por lo que permanece impermeable a esos juegos ("No frecuentando en ese tiempo a nadie del mundo intelectual o musical, estaba mal informada sobre lo que era conveniente vituperar o alabar", "Correspondencia”, op. cit., pp. 105-106). Asiste a todas las funciones de esa temporada, no se pierde ni una sola representación (“Tímidamente me decía: ‘yo creo que esto me gusta", ibid.). Hacia el final, ya ha formado su juicio estético: "Hasta que un buen día la duda ya no fue posible: 'Aquello me gustaba"', ibid. El gusto moderno se afirma como el acto de coraje de una autodidacta. La escena del estreno, por otra parte, permite visualizar su lugar respecto del campo cultural en 1913 así como el recorrido que va a hacer a partir esa noche hasta su regreso a París en 1929. En el estreno están aquellos que serán más tarde sus amigos, pero que en ese momento ella no frecuenta, como Eugenia Errazuriz, Picasso, Cocteau y otros. Asisten, por otra parte, como menciona Beatriz Sarlo en el análisis que hace de esta escena, personajes importantes de la literatura como Apollinaire y Gertrude Stein ("Victoria Ocampo o el amor de la cita", La máquina cultural [1998]. Barcelona: Seix Barral, 2007, pp. 77-84). Si bien Sarlo propone pensar en un trayecto que iría del palco (donde sitúa a Ocampo, junto al "beau monde") a la platea (en donde están "los estetas"), Victoria, tal como se lo escribe al señor X, está sentada en las primeras filas de la platea, es decir con estos últimos, pero adelante de todo.

150. "Una música que gusta a los invertidos preferentemente, denuncia sus propios vicios”, Claridad, Buenos Aires, nํ138, 10 de julio de 1927, snp.

151. Victoria Ocampo, “Correspondencia”, op. cit., p. 104.

152. En 1925, Eduardo Juan Bullrich escribe en Martín Fierro: "Estas ediciones de mal gusto y de ningún mérito se hacen en Francia la exportación, para el "nouveau riche" y para los principiantes y son despreciadas por los verdaderos bibliófilos, ante todo, hombres de 
gusto refinado", "Una venta de libros", Martín Fierro, Buenos Aires, nº 18, 26 de julio 1925, pp. 6-7.

153. Igor Stravinsky, "Beethoven", SUR, nº 18, Buenos Aires, marzo de 1936, p. 16. La Editorial Sur había publicado en 1935 Chroniques de ma vie y publica en 1936 Nouvelles chroniques de ma vie.

154. Victoria Ocampo, "Correspondencias", op. cit., p. 100.

155. Ibid., p. 101. Hay sin dudas cierta pose o cierto gesto de distinción respecto de su clase en el hecho de traducir la cita de Valéry. Lo más espontáneo, sin dudas, hubiera sido copiarla en la versión original. En ese sentido, cuando se habla de ostentación o exhibicionismo lingüístico en el uso que hace Ocampo de las lenguas extranjeras, generalmente se deja de lado la perspectiva de Ocampo, desde la cual traducir al español da cuenta, por un lado, de la ostentación de un saber y, por el otro, de una actitud condescendiente, e incluso middle-brow, hacia el lector.

156. Victoria Ocampo, Cartas a Angélica, op. cit., p. 50

157. Ibid., p. 51

158. Años más tarde leerá en la autobiografía de George Eliot una reflexión bastante fina sobre el rechazo que produce que un familiar sostenga posturas para uno inconcebibles con el tono, los gestos y las maneras de uno mismo, ibid., p. 239.

159. Ibid., p. 124.

160. Ibid., p. 125.

161. "[...] milieu de gens riches et snobs, de la haute couture, des artistas d'avant-garde et des hommes politiques genre Bergery (à cause de Bétina sa maîtresse, ancien modèle de Schiaparelli). Terrible! [] Apres et légers. Sans chaleur, sans amour. N'accordant de l'importance qu'à un joli cendrier, à un Picasso (c'est déjà mieux), à une robe de Schiap, à un mouchoir d'Edwards and Buttler, à un clip de chez Cartier... à des choses ; tout ça, dans les moments actuels, devient indescriptible, comme la neige qui fond dans les rues de Paris. De la saleté." Odile Felgine (ed.), Roger Caillois y Victoria Ocampo, Correspondance: 1939-1978., op. cit., pp. 71-72. La carta está fechada el 15 de agosto de 1940.

162. Ibid.

163. Ibid., p. 73.

164. Victoria Ocampo, Cartas a Angélica, op. cit., p. 93.

165. Ibid., p. 165. La carta está fechada el 30 de noviembre de 1963.

166. Ibid.

167. Ibid., p. 93.

168. "Desde luego, hay un sutil y subterráneo reproche en lo de la princesa del buen gusto. [...] Respeto la América profética que, según Waldo, lleva Glusberg en el corazón. Esto no impide que yo lleve la mía, con tanto derecho como él, a pesar de no ser inmigrante", "They are fighting in the center" (Contesto a La Opinión), op. cit., p. 289.

169. Omar Corrado hace un estudio excelente sobre el paralelo entre Victoria Ocampo y la princesa de Polignac. Nótese la siguiente observación: "Otra característica emparenta las activistas musicales de París: Polignac es estadounidense; Noailles, de padres rumanogriegos (aunque nacida en París); Errázuriz, chilena. Se trata de mujeres de origen 'periférico', fortuna considerable, experiencia cosmopolita, interés particular por la música y fuerte inserción en el campo cultural en el que actúan, todos rasgos compartidos por Victoria", op. cit.

170. Victoria Ocampo, Índice de SUR 1931-1966, op. cit., p. 12. El encuentro con T. S. Eliot está narrado en "Carta a un joven poeta americano", Testimonios, Séptima serie (1962-1967). Buenos Aires: Sur, 1967, pp. 166-170. 
171. Adolfo Bioy Casares, Borges, op. cit., p. 742.

172. Ibid., p. 770. Aquí la mención quizá aluda a Marcos Victoria, lo que no altera el sentido para nosotros, ya que en otra oportunidad registra Bioy: BORGES: "Es claro. Para Aita o Galtier es to be or not to be. En cuanto a Victoria, en sus dos formas de Ocampo y de Marcos, qué más quiere. Si Victoria insistía en que la fotografiaras con esa payasa de Vivien Leigh...", p. 771.

173. Witold Gombrowicz, Diario, op. cit., p. 658.

174. Ibid., p. 662.

175. Sobre el malentendido de la invitación, se ríe Borges. "Victoria lo llamó por teléfono para contarle que el PEN Club no la había invitado al Coloquio de Escritores de Mar del Plata. Que ella había llamado a Galtier, el secretario del PEN, y le había preguntado qué significaba esta omisión. Que Galtier había balbuceado excusas. Que ahora ella leyó en los diarios que la han invitado pero que, como no recibió la notificación oficial, está incómoda y no sabe qué hacer. BORGES (a las carcajadas ) : ¿¿Te das cuenta? Me llamó ella misma, para decirme todo esto. Dijo que se pasa la mitad del año en Mar del Plata, Entonces, ¿para qué quiere ir ? ¿Cómo no prevé que no será divertido? Otra que estará como loca con el coloquio es Lisa Lenson. Para mucha gente estos congresos son bienvenidos sustitutos de la literatura, que realmente no les gusta." Ibid., p. 843. El discurso de Ocampo, por otra parte, se encuentra en las Actas publicadas del PEN Club, Coloquio de Buenos Aires 1962. Buenos Aires: P.E.N. Club de la Argentina, 1963, p. 248.

176. Ibid., p. 742.

177. "Dado que en la sociedad todo es funcional, a la demanda social de espiritualidad le responde cierta producción de superioridad, de grandeza, y surge un nuevo tipo de funcionario: el funcionario del espíritu", Witold Gombrowicz, Diario, op. cit., p. 666.

178. José Bianco, op. cit., p. 234.

179. Victoria Ocampo, Cartas a Angélica, op. cit., p. 160. La carta está fechada el 29 de noviembre de 1963.

180. Victoria Ocampo, “El tiempo de Malraux”, Testimonios, Décima Serie (1975-1977), op. cit., p. 131.

181. Sin firma, “A los 70 y pico... una niña terrible”, op. cit., p. 41.

182. La comida es muy importante en Ocampo y merece un estudio aparte. Con T. S. Eliot también consigue encontrar su punto de unión a través de una torta, "Carta a un joven poeta americano", op. cit., p. 169.

183. "Yo he soñado que a esta casa vinieran y hasta vivieran en ella escritores", Diálogo entre las culturas, SUR, no 342, enero-junio 1978, p. 19.

184. José Bianco, op. cit., p. 234.

185. Elena Croce, op. cit., p. 10.

186. Victoria Ocampo, "El tiempo de Malraux", ibid.

187. Witold Gombrowicz, Diario, op. cit., p. 199.

188. Victoria Ocampo, Índice de SUR 1931-1966, op. cit., p. 3.

189. Ibid., p. 11.

190. Flaminia Ocampo, Victoria y sus amigos, Buenos Aires: Aquilina, 2009, p. 47.

191. “[Mi padre] murió pocos meses después, en 1931, año en que aparecería SUR. Conocía mi proyecto. 'Te vas a fundir -me dijo -. Te conozco.' Me hablaba como a un hijo jugador”, "They are fighting in the center" (Contesto a La Opinión), Testimonios. Décima serie 1975-1977. Buenos Aires: Sur, 1978, p. 287.

192. Witold Gombrowicz, Diario, op. cit., p. 198. 
193. En 1930, en París, cuando visita la casa de Gourgaud "(descendiente del general que acompañó a Napoleón en Santa Helena)", reconocer la impresionante colección de arte "(Picassos, Braques, Matisses, Cézannes, Watteaus, etc., etc.)" no asegura su aprobación: "La casa lujosa pero con terribles fallas de gusto", Cartas a Angélica, op. cit., p. 17. En 1946, Cuando va a lo de Valenti en Nueva York, dice "cuyo apartamento en 5th Av. es bastante lujoso y de mal gusto", ibid., p. 77. El horror al lujo ostentoso era un rasgo compartido por su clase: "BIOY: Uno de los inconvenientes de la pobreza es que induce a dar excesiva importancia al lujo: la admiración por el lujo sólo es perdonable en personas muy pobres", Adolfo Bioy Casares, op. cit., p. 403.

194. Witold Gombrowicz, Diario, op. cit., p. 199.

195. Rubén Darío, "La evolución del rastacuerismo", op. cit., pp. 143-150.

196. Víctor Goldgel, op. cit., p. 242.

197. Sobre el cosmopolitismo de Rubén Darío ver Mariano Siskind, Cosmopolitan Desires: Global Modernity and World Literature in Latin America, vol. 14, Evanston, Northwestern University Press, 2014. Sobre el efecto de la noción de rastacuero en el poeta nicaragüense, ver pp. 220-222.

198. Rubén Darío, op. cit., p. 147.

199. Victoria Ocampo, "Palabras francesas", Testimonios primera serie, op. cit., p. 21.

200. El episodio aparece narrado al comienzo de "Palabras francesas", uno de sus artículos más conocidos, publicado en SUR y luego en la primera serie de sus Testimonios, en 1935. Al nacer su prima, le piden que elija un nombre. Victoria propone Geneviève, sin saber que, como le explica su tía, "es un nombre español el que hace falta". "Ese nombre en francés es muy bonito, efectivamente, ¿pero te parece que en español Genoveva sea igual de lindo?", le pregunta su tía. "No", responde Ocampo niña. Geneviève es distinguido y remite a la heroína infantil que compartía con Proust, pero Genoveva es rústico y remite a una antigua sirvienta desfavorecida. Ver el análisis de Mariano López Seoane sobre esta escena en "La imposibilidad de ser fiel: el drama de la traducción en Victoria Ocampo", Cuadernos del Sur, nº 39, Bahía Blanca, 2009.

201. La nociones de recién llegada y de autodidacta nutren su marcha feminista. La pista aparece en varios textos. Un ejemplo: "Acontece esto como con la diferencia que se suele observar en la Argentina entre los hijos de emigrantes y los de familias afincadas en el país desde hace varias generaciones. Los primeros tienen una susceptibilidad exagerada con respecto a no sé qué falso orgullo nacional. Los segundos son americanos hace tanto tiempo que no lo demuestran con ostentación. Pues bien, Virginia, debo confesar que no me siento aun totalmente liberada del equivalente de esa susceptibilidad, de ese falso orgullo nacional, en lo que atañe a mi sexo. ¡Quién sabe si al respeto no soy una parvenue !", Virginia Woolf en su Diario. Buenos Aires: Sur, 1974, pp. 106-107.

202. Victoria Ocampo, Cartas a Angélica, op. cit., p. 171.

203. Ibid.

204. Vies croisées de Victoria Ocampo et Ernest Ansermet : Correspondance, 1924-1969, op. cit., p. 59.

205. "Yo podría ponerle como título a mis Memorias la divisa de María Estuardo, usándola al revés: 'En mi comienzo está mi fin”", Autobiografía I. El archipiélago. Buenos Aires: Sur, 1979, pp. 65-66.

206. Primera Plana, $\mathrm{n}^{\circ} 168,15-21$ de marzo, 1966.

207. Sobre esta noción de cultura de invernadero, ver sus intercambios con Alfred Métraux. 
208. En un momento Juan Goyanarte, un escritor, comerciante y hacendado de Bahía blanca, entra como accionista de SUR, pero ella vuelve a comprarle las acciones poco tiempo después porque creía que aceptar su inversión bajaba la calidad literaria de la revista.

209. Esta partitura tenía un valor especial para Ocampo. En esta ópera de Igor Stravinsky con libreto de André Gide, Victoria hace el papel de recitante en Buenos Aires (mayo 1936), en Brasil (1936) y en Florencia (1939). En 1953, Stravinsky la vuelve a convocar, pero Ocampo no puede viajar porque el régimen peronista le retiene el pasaporte. En la correspondencia con Caillois antes citada se menciona la pelea que habría habido entre Gide y el compositor ruso, en la que habría intervenido con cierto éxito Paul Valéry, porque al primero no le había gustado lo que el segundo había hecho con su libreto (libreto que, para la representación en el Teatro Colón, Borges había traducido al español), p. 457. En la correspondencia inédita entre Ocampo y Stravinsky, por otra parte, se observa la confianza que Ocampo tenía con su amigo músico: le pide, por ejemplo, que adelante la función de Río de Janeiro porque cree que en esos días va a tener su menstruación y nunca sabe cuánto le puede llegar a doler.

210. Victoria Ocampo, Cartas a Angélica, op. cit., p. 117. La carta está fechada el 9 de junio 1962.

211. Ibid., p. 160. La carta está fechada el 29 de noviembre de 1963.

212. Ibid., p. 154. 22 de noviembre de 1963.

213. Ibid., p. 120.5 de julio de 1962.

214. Victoria Ocampo, "Después de 40 años”, op. cit.

215. Jorge Luis Borges, "Página preliminar" en José Bianco, op. cit., p. 9.

216. Victoria Ocampo, “Después de 40 años”, Testimonios Novena Serie (1971-1974), Buenos

Aires: Sur, 1975, p. 210. Las siguientes citas del párrafo pertenecen a este artículo. Nótese, este discurso, junto con los demás que dio en cada aniversario de la revista, vuelve a publicarse después de su muerte en Cincuentenario 1931-1981. Literatura Hispanoamericana, SUR, no 349, julio-diciembre 1981.

217. Julio Cortázar, “Victoria Ocampo: Soledad sonora”, SUR, no 192-194, octubrediciembre 1950, pp. 294-297.

218. Victoria Ocampo, “Después de 40 años”, op. cit., p. 207.

219. “Y verlo a Caillois: ¿te das cuenta, verlo a Caillois?”, le dice a Bioy, aliviado de no haber tenido que viajar a Europa y dejar Buenos Aires ("Qué maniático, París es una gran ciudad", responde Bioy); un esnobismo raro el de Borges con la capital que todavía hoy puede observarse en algunos porteños de la vieja oligarquía radical.

220. Sobre la cuestión de las lenguas en Ocampo, ver Sylvia Molloy, "El teatro de la lectura: cuerpo y libro en Victoria Ocampo", Acto de presencia, México, Fondo de Cultura Económica, 1996, pp. 78-106; Beatriz Sarlo, "Victoria Ocampo o el amor de la cita", La máquina cultura, op. cit., pp. 77-148; María Teresa Gramuglio, “Victoria Ocampo y los conflictos de la cultura argentina", Prismas. Revista de historia intelectual 2, Universidad Nacional de Quilmes, 1998, pp. 231-234; Magdalena Cámpora, “

Borges y el idioma de los franceses", Cuadernos LIRICO [En línea], 12 | 2015, Puesto en línea el 23 enero 2015, consultado el 07 septiembre 2017. URL : http://lirico.revues.org/2002 ; DOI : 10.4000/lirico.2002 y artículo citado de Mariano López Seoane, "La imposibilidad de ser fiel: el drama de la traducción en Victoria Ocampo", ver nota 192. Sobre el cosmopolitismo de Victoria Ocampo, ver Juan José Sebreli, El asedio la modernidad. Crítica del Relativismo Cultural, Barcelona, Ariel, 1992; también Gonzalo Aguilar, op. cit. 221. Jorge Luis Borges, “Un destino”, op. cit., p. 51. 
222. Victoria Ocampo, “Al lector”, Testimonios. Décima serie 1975-1977, op. cit., p. 7.

\section{ABSTRACTS}

Was Victoria Ocampo a snob? Argentine press and critiques have always considered her as such, from her earliest steps in culture in the 1920's and all throughout her life, until her death in 1979. Posterity has also reserved her that first epithet. But what does being a snob mean? Is it possible to define senses, uses and values in her well-known snobbism? How can one distinguish the snobbism she incarnated from the one that others decided to see in her figure? The director of Sur was a rich, elitist and cosmopolitan woman, who did not reject the beliefs of her patristic class and had, from time to time, sporadic and trivial snob gestures. But what she really practiced with devotion and rigorous asceticism was the snobbism of modernity, whose specificities have gradually been lost in the collective, indiscriminate yet long-lived projection that eclipses her figure. As Paul Valéry used to say: "It is impossible to understand and to punish at the same time". Against this dimension of her reception in Argentina, it is necessary to discriminate, conceptualize and order different aspects in Ocampo's snobbism, in order to confront it with that by which she was judged as a paradigmatic figure. After a quick theoretical outlook on the notion of snobbism, and a presentation of Ocampo as a social figure in Buenos Aires' cultural field in the 1920s (that is, before she founded and directed magazine SUR), this article intends to inquire into the significance, misunderstandings, uses and benefits from Victoria Ocampo's snobbism.

¿Fue Victoria Ocampo esnob? Así la concibió la crítica y la prensa argentina desde los primeros pasos de su labor en la cultura de este país, en los años 20 , hasta el final, poco antes de su muerte en 1979. La posteridad, de igual manera, conservó para ella aquel primer epíteto. ¿Pero qué significa que fue esnob? ¿Es posible delimitar sentidos, usos y valores en su mentado esnobismo ? ¿Y cómo diferenciar el esnobismo que ella encarnó de aquel que los demás juzgaron ver en su figura? La directora de SUR fue una mujer rica, elitista y cosmopolita que no rechazó todas las creencias de su clase patricia y tuvo, además, esporádicos y triviales gestos esnobs. Pero lo que cultivó con devoción y rigor ascético fue el esnobismo de la modernidad, cuyas particularidades se han ido perdiendo en la proyección colectiva, indiferenciada y longeva que eclipsa su figura. "Es imposible comprender y castigar al mismo tiempo", anota Paul Valéry. Contra este aspecto de su recepción en Argentina, empieza el trabajo de diferenciar, conceptualizar y ordenar diferentes aspectos del esnobismo de Ocampo, a fin de poder cotejarlo con aquel del que se la juzgó el paradigma. A través de un breve panorama teórico sobre la noción de esnobismo, y de una presentación de Ocampo como figura social en el campo cultural de Buenos Aires en los años 20 (es decir, antes de que fundase y dirigiese la revista SUR), este trabajo se preocupa por indagar los alcances, malentendidos, usos y beneficios del esnobismo de Victoria Ocampo.

Victoria Ocampo, était-elle une snob ? C'est ainsi qu'elle a été comprise par la critique et par la presse argentine depuis ses premiers spas dans la gestion culturelle de son pays, dans les années 1920, et jusqu'à sa mort en 1979. La postérité lui a également réservé cette première épithète. Mais que signifie-t-il donc d'être "snob" ? Est-il possible de délimiter des sens, des us et des valeurs dans son célèbre snobisme ? Comment différencier le snobisme qu'elle a incarné de celui que les autres ont jugé voir en sa figure ? La directrice de SUR a été une femme riche, élitiste et cosmopolite, qui n'a pas rejeté les croyances de sa clase patricienne et qui même eu, parfois, les 
gestes triviaux et frivoles d'une snob. Mais ce qu'elle a cultivé, avec dévotion et ferveur ascétique, ce fut surtout le snobisme de la modernité, dont les particularités se sont peu à peu confondues dans la projection collective, indifférenciée et d'une grande longévité qui éclipsent sa figure. À l'encontre des particularités de sa réception en Argentine, commence le travail de différencier, de conceptualiser et d'ordonner les différents aspects du snobisme d'Ocampo, afin de le confronter avec celui par lequel elle a été jugée comme figure paradigmatique. «Il est impossible de comprendre et de châtier en même temps ", disait Paul Valéry. Après un bref tour d'horizon théorique sur la notion du snobisme, et d'une présentation d'Ocampo en tant que figure sociale dans le champ culturel portègne des années 1920 (c'est-à-dire, avant qu'elle ne fonde et dirige la revue SUR), ce travail entend sonder la portée, les malentendus, les us et les bénéfices du snobisme de Victoria Ocampo.

INDEX

Mots-clés: Victoria Ocampo, snobisme, réception, SUR, biographies, histoire culturelle argentine

Keywords: Victoria Ocampo, snobism, reception, SUR, biographies, Argentinian cultural history Palabras claves: Victoria Ocampo, esnobismo, recepción, SUR, biografías, historia cultural argentina

\section{AUTHOR}

\section{VICTORIA LIENDO}

Université Paris 8 